\title{
REVIEW ARTICLE OPEN The interrelationship between cerebral ischemic stroke and glioma: a comprehensive study of recent reports
}

\author{
Mrinal K. Ghosh ${ }^{1}$, Dipankar Chakraborty ${ }^{1}$, Sibani Sarkar ${ }^{1}$, Arijit Bhowmik $^{2}$ and Malini Basu ${ }^{3}$
}

Glioma and cerebral ischemic stroke are two major events that lead to patient death worldwide. Although these conditions have different physiological incidences, $\sim 10 \%$ of ischemic stroke patients develop cerebral cancer, especially glioma, in the postischemic stages. Additionally, the high proliferation, venous thrombosis and hypercoagulability of the glioma mass increase the significant risk of thromboembolism, including ischemic stroke. Surprisingly, these events share several common pathways, viz. hypoxia, cerebral inflammation, angiogenesis, etc., but the proper mechanism behind this co-occurrence has yet to be discovered. The hypercoagulability and presence of the D-dimer level in stroke are different in cancer patients than in the noncancerous population. Other factors such as atherosclerosis and coagulopathy involved in the pathogenesis of stroke are partially responsible for cancer, and the reverse is also partially true. Based on clinical and neurosurgical experience, the neuronal structures and functions in the brain and spine are observed to change after a progressive attack of ischemia that leads to hypoxia and atrophy. The major population of cancer cells cannot survive in an adverse ischemic environment that excludes cancer stem cells (CSCs). Cancer cells in stroke patients have already metastasized, but early-stage cancer patients also suffer stroke for multiple reasons. Therefore, stroke is an early manifestation of cancer. Stroke and cancer share many factors that result in an increased risk of stroke in cancer patients, and vice-versa. The intricate mechanisms for stroke with and without cancer are different. This review summarizes the current clinical reports, pathophysiology, probable causes of co-occurrence, prognoses, and treatment possibilities.

Signal Transduction and Targeted Therapy (2019)4:42

; https://doi.org/10.1038/s41392-019-0075-4

\section{INTRODUCTION}

Cerebral ischemia, also known as cerebral ischemic stroke or cerebrovascular ischemia, is the most common type of stroke $(>80 \%)$ and is the second leading cause of death, dementia, and disability worldwide. ${ }^{1}$ This condition occurs when a sudden obstruction of the blood supply or a reduction of normal cerebral blood flow (CBF) leads to brain injuries. ${ }^{2}$ The sudden brain tissue damage due to a low supply of nutrients and hypoxia is also known as cerebral infarction and is further divided into two major categories according to origin. Focal cerebral ischemia, microischemia, or local cerebral infarction is caused by blockage of a blood vessel ${ }^{3}$ due to onsite blood clot formation (thrombus) ${ }^{4}$ or a blood clot that originates in a different place (embolus, sporadic), ${ }^{5}$ whereas the global cerebral ischemic condition originates due to hypoperfusion or a drastic reduction of CBF in the overall brain caused by large-artery atherosclerosis, complete obstruction of the carotid arteries, cardiac arrest, chronic hypoxemia, or seizures. ${ }^{6}$

Several intracranial malignant tumors occur in the human brain, of which glioma is the deadliest and rarely curable form and is resistant to radiotherapy and chemotherapy ${ }^{7}$ According to the World Health Organization (WHO), glioma can be classified into four different grades (I-IV), where grade I includes pilocytic astrocytoma, grades II-III include diffuse or anaplastic astrocytoma and oligodendrogliomas, and grade IV includes most malignant glioblastomas (GBMs). ${ }^{8,9}$ Despite the major driver mutations (TP53, IDH1, EGFR, PTEN, Rb, RTKs, and others), several mechanical or molecular signaling alterations are found in all grades of glioma and within its microenvironment. ${ }^{10}$ The postoperative approximate survival time for GBM patients is $\leq 15$ months, and only $26.5 \%$ of patients survive for $>2$ years after diagnosis. ${ }^{11}$

In this review, our major aim is to document the interrelationship between cerebral ischemic stroke and glioma based on a comprehensive review of current knowledge, which is sequentially discussed in detail. First, we briefly discuss the relationship between cerebral ischemia and glioma that could explain the interplay between the two diseases. Second, we discuss the effects of cerebral ischemia on glioma development and progression. Third, we elaborate on the effects of reactive oxygen species (ROS), reactive nitrogen species (RNS), and the neurovascular unit on brain tumors. Fourth, we focus on glioma-dependent cerebral ischemic stroke and brain injuries. Finally, plausible pharmacological interventions towards therapeutic strategies are discussed.

\section{INTERPLAY BETWEEN CEREBRAL ISCHEMIA AND GLIOMA: WHAT DO CLINICAL REPORTS REVEAL?}

The relationship between cerebral ischemia and glioma is still ambiguous based on molecular mechanisms, but several clinical

\footnotetext{
${ }^{1}$ Signal Transduction in Cancer and Stem Cells Laboratory, Division of Cancer Biology and Inflammatory Disorder, Council of Scientific and Industrial Research-Indian Institute of

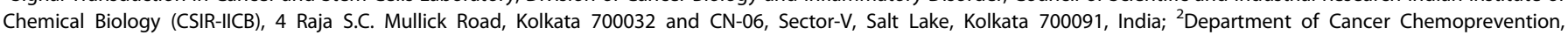

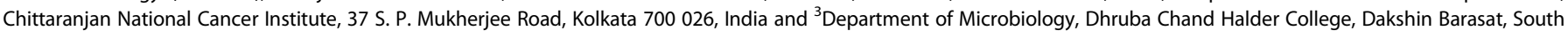
24, Paraganas 743372, India

Correspondence: Mrinal K. Ghosh (mrinal.res@gmail.com)
}

Received: 30 April 2019 Revised: 26 August 2019 Accepted: 29 August 2019

Published online: 12 October 2019 
reports and case studies have indicated that glioma and cerebral ischemia can facilitate each other with respect to occurrence. It has been reported that the location of the tumor inside the brain (insula, operculum, and temporal lobe) and repeated resection during glioma therapy can increase the risk of ischemic injuries and other neurological deficits. ${ }^{12} \mathrm{~A}$ recent report based on clinical cohort studies suggests that the chance of the diseases occurring together reaches $9 \%$ compared with $2.7 \%$ in the control population, and the risk of developing brain cancer (especially glioma) is also higher in stroke patients. ${ }^{13}$ Another clinical cohortbased study on 3680 noncancerous adults with no disabling cerebral infarction reported the development of brain cancer (glioblastoma) with a mortality rate that is threefold higher than that of the control cohort in the postischemic period. ${ }^{14}$ Another case study of a 73-year-old woman with a history of atrial fibrillation and mechanical aortic valve replacement showed primary glioma development within the territory of a previous ischemic infarction. ${ }^{15} \mathrm{~A}$ similar result of the sudden onset of an acute ischemic lesion near the tumor area was reported in another case study of a 77-year-old woman suffering from an anterior temporal lobe tumor. ${ }^{16}$ A different report stated that two adult patients with supratentorial glioblastomas developed an ischemic stroke on the tumor site. ${ }^{17,18} \mathrm{~A}$ recent case study reported that the risk of neurodegeneration and ischemic lesions increases after resection of recurrent tumors. ${ }^{19}$ The case of an anaplastic astrocytoma patient showed acute onset ischemic stroke-like symptoms. ${ }^{20}$ In another interesting case, a 79-year-old woman with a history of atrial fibrillation and coronary heart disease developed glioblastoma multiforme (GBM) at the site of a previous infarction 6 years after the onset of right hemiplegia. ${ }^{21}$ Cerebral ischemia might occur due to embolus metastatic glioma cells, as reported recently. ${ }^{22}$ Another unusual case of acute ischemic infarction of the middle cerebral artery was caused by a proliferating glioma mass. ${ }^{23}$ In certain cases, it is notably difficult to distinguish the early symptoms of stroke and glioma, which might lead to improper therapy. Several reports worldwide present these pseudo-symptoms of glioma and cerebral ischemia. ${ }^{24,25}$ Another interesting case is a woman from India who was primarily diagnosed as a cerebral stroke patient but was later found to exhibit glioma development instead of stroke symptoms. ${ }^{26}$
The most widely accepted model that connects ischemia and glioma is based on the common hypoxic condition that occurs in both situations. ${ }^{13,19,27,28}$ Cerebral ischemia due to obstruction in the vasculature locally or globally causes low oxygen tension in the ischemic regions and results in hypoxia, whereas a highly proliferating glioma cell mass has poor vasculature inside its core, leading to a hypoxic core region that is deprived of oxygen. ${ }^{29}$ The exact mechanisms of this co-occurrence or interplay are still in the nebulous phase, but certain possible mechanisms, e.g., astrocyte activation, ${ }^{30,31}$ reactive gliosis, ${ }^{32-34}$ angiogenesis ${ }^{35-37}$, and changes in perivascular and perinecrotic niches ${ }^{38-40}$ due to cerebral ischemia, are reported as a consequence for glioma development. In this review, all of the possible methods of interplay are described in a sequential manner (Fig. 1).

\section{CEREBRAL ISCHEMIA, HYPOXIA AND GLIOMA: ROS AND RNS CONNECTION}

ROS are metabolic byproducts, e.g., hydroxyl radicals (HO•), alkoxyl radicals (RO•), hydrogen peroxide $\left(\mathrm{H}_{2} \mathrm{O}_{2}\right)$, and hydroperoxyl radicals $\left(\mathrm{HO}_{2} \cdot\right)$, originating from different sources in hypoxic ${ }^{41}$ and hyperoxic situations with condition-dependent functions. ${ }^{42-44}$ Multiple sources for ROS production are reported in both ischemia and glioma, and both conditions share a common network of signaling for ROS production and downstream functions.

In the cerebrovascular unit, the hypoxic situation induces astrocytes, microglia, pericytes, and even neurons to produce ROS and RNS (NO, ONOO $\left.{ }^{-}\right){ }^{45-47}$ ROS, together with RNS, take a lead role in regulation of the hypoxic situation in the affected tissue mass.

\section{Mitochondrial ECT}

In mitochondria, electrons flow into the sequential Electron transport chain (ETC) (complex I, II, III) and ultimately meet up with $\mathrm{O}_{2}$ at complex IV for ATP synthesis and $\mathrm{H}_{2} \mathrm{O}$ production via the oxidative phosphorylation (OXPHOS) process. ${ }^{48,49}$ However, in the case of oxidative stress or other pathophysiological conditions, more leaky electrons are produced, and ROS are mainly generated from complex I, III, and glycerol 3-phosphate dehydrogenase. ${ }^{50}$ During oncogenesis, several cancer-specific external stimuli or

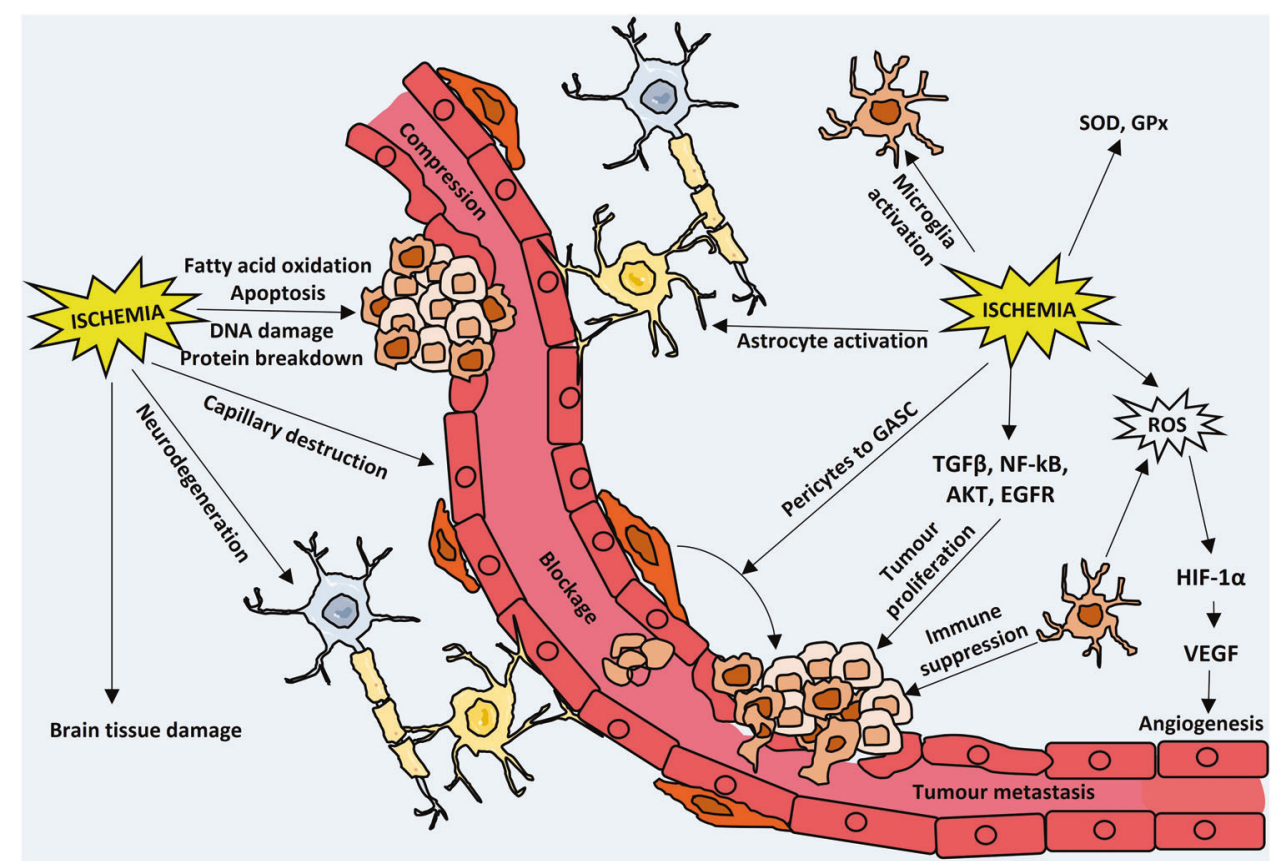

Fig. 1 Bi-phasic role (i.e., detrimental and tumor promoting) of cerebral ischemic hypoxia and glioma development 
signaling alterations (e.g., TNF- $a$, STAT3) cause a decrease in the mitochondrial membrane potential that hampers the components of ETC such that ROS generation is promoted on a large scale. ${ }^{51,52}$ Reports exist of mutation in components of the ETC complexes, and mtDNA can cause a high level of ROS production. ${ }^{53,54}$

\section{Cytoplasmic NOX}

The NADPH oxidase (NOX) family of proteins is one of the main producers of ROS in several cancers and ischemic stroke. ${ }^{55}$ NOXs are membrane-bound proteins with a C-terminal NADPH/FADbinding domain and $\mathrm{N}$-terminal transmembrane tandem heme groups. ${ }^{56}$ It is reported that NOX2 (gp91phox) and its homologs (Nox1, 3, 4, and 5 and Duox $1 / 2$ ) require 222 phox as a cosubunit and catalyze superoxide $\left(\mathrm{O}_{2}{ }^{-}\right)$generation via a NADPH-dependent pathway, which is subsequently converted to $\mathrm{H}_{2} \mathrm{O}_{2} \cdot{ }^{57,58}$ However, Duox $1 / 2$ has an EF-hand domain for calcium binding instead of the heme group. ${ }^{59}$ Specific signals (viz., TGF- $\beta_{,}{ }^{60}$ AKT, ${ }^{61} \mathrm{PKC}^{62}$ MAPK, ERK, etc.) induce conformational changes in the NOX complex in a phosphorylation-dependent manner and allow production of a notably large amount of ROS. ${ }^{63}$

\section{Peroxisomes}

The peroxisome is one of the major sites for $\alpha$ - and $\beta$-oxidation of fatty acids, polyamine oxidation, phospholipid and glyoxalate metabolism, catabolism of amino acids, the pentose phosphate pathway, etc. ${ }^{64}$ The peroxisome contains several enzymes (e.g., Acyl-CoA oxidases, D-amino acid oxidase, urate oxidase, aspartate oxidase, polyamine oxidase, xanthine oxidase (XO), L-alpha-hydroxy acid oxidase, pipecolic acid oxidase, trihydroxycoprostanoyl-CoA oxidase, etc.) that produce $\mathrm{H}_{2} \mathrm{O}_{2}$, $\mathrm{O}_{2}{ }^{-}$, and $\mathrm{OH} \cdot$ as normal metabolic byproducts. ${ }^{65}$ The antioxidant defense system inside the peroxisome maintains homeostasis against those ROS, but in ischemia and glioma, this homeostasis is disturbed due to oxidative stress, which alters signaling and mutation and produces overactivation of several enzymes inside this organelle to give rise to an increased level of ROS inside the cell. ${ }^{66,67}$

\section{Xanthine oxidase}

$\mathrm{XO}$ is a homodimeric metalloprotein with one flavin adenine dinucleotide (FAD) cofactor for purine oxidation and a molybdopterin cofactor (Moco) for $\mathrm{NAD}^{+}$reduction flanked by two nonidentical iron-sulfur redox centers. ${ }^{68,69}$ In glioma and ischemia, the hypoxic condition and low $\mathrm{pH}$ allow $\mathrm{XO}$ to form a large amount of $\mathrm{H}_{2} \mathrm{O}_{2}, \mathrm{O}_{2}{ }^{-}$, and $\mathrm{OH} \cdot$ via the Haber-Weiss-Fenton reaction. ${ }^{70-72}$

Cytochrome P450 (CYP)

CYPis a monooxygenase with a heme (FellI) prosthetic group, ${ }^{73,74}$ and its isoforms in different regions of the body regulate the biotransformation pathway of several endogenous and exogenous toxins, chemicals, xenobiotics, and organic molecules. This system can generate different ROS species $\left(\mathrm{H}_{2} \mathrm{O}_{2}, \mathrm{O}_{2}-, \cdot \mathrm{O}_{2}{ }^{-}, \mathrm{OH}^{-}\right)$via abnormal uncoupling of the normal metabolic pathways due to hypoxia-specific signals. $^{75-77}$

\section{Lysyl oxidases (LOXs)}

Protein-lysine 6-oxidase, also known as LOX, produces $\mathrm{H}_{2} \mathrm{O}_{2}$ as a byproduct during crosslinking between cell-matrix protein elastin and collagen using the lysyl tyrosylquinone cofactor. $^{78}$ The enzyme is regulated by Hif- 1 or Hif- 2 and generates ROS and induces metastasis and cell-matrix adhesion via the FAK/Src signaling pathway in both ischemia and glioma. ${ }^{79-82}$

\section{Involvement of other signaling pathways in ROS and RNS generation}

ROS can be regulated by the Ras-Raf-MEK pathway via transcriptional regulation of Nox1 by the GATA-6. ${ }^{83,84}$ It is also reported that transcriptional enhancement of HSF1 by Ras upregulates the SESN1 and SESN3 genes and peroxiredoxins for ROS production. ${ }^{85}$ TGF $\beta$ increases ROS production via activation of GSK3 $\beta$ and the mTOR pathway in mitochondria, and by suppressing antioxidant enzymes such as SOD and glutathione peroxidase (GPx) ${ }^{86,87}$ Nuclear factor-KB (NF-KB) can increase ROS production via a positive feedback loop of TNF regulation. ${ }^{88,89}$ c-Myc can regulate ROS production via two mechanisms, i.e., ROS production via alteration of mitochondrial structure and metabolism with the aid of AMPK and PRx-Romo1 pathway regulation. ${ }^{90-92}$ It is also reported that the ROS level can be upregulated by the $\beta$-adaptin/c-Myc pathway. ${ }^{93}$ The PI3K/mTOR and STAT5 pathway is activated by Bcr-Abl to increase mitochondrial ROS production ${ }^{94,95}$ (Fig. 2).

However, ischemic hypoxia-induced constitutive or inducible nitric oxide (NO) production is enhanced due to glutamatergic receptor-mediated high calcium concentration and calmodulindependent upregulation of nitric oxide synthase (nNOS, eNOS, and iNOS). ${ }^{96,97}$ Peroxynitrite $\left(\mathrm{ONOO}^{-}\right)$is generated by the reaction of $\mathrm{NO}$ and ROS. ${ }^{98}$ Neuronal NOS (nNOS) is constitutively

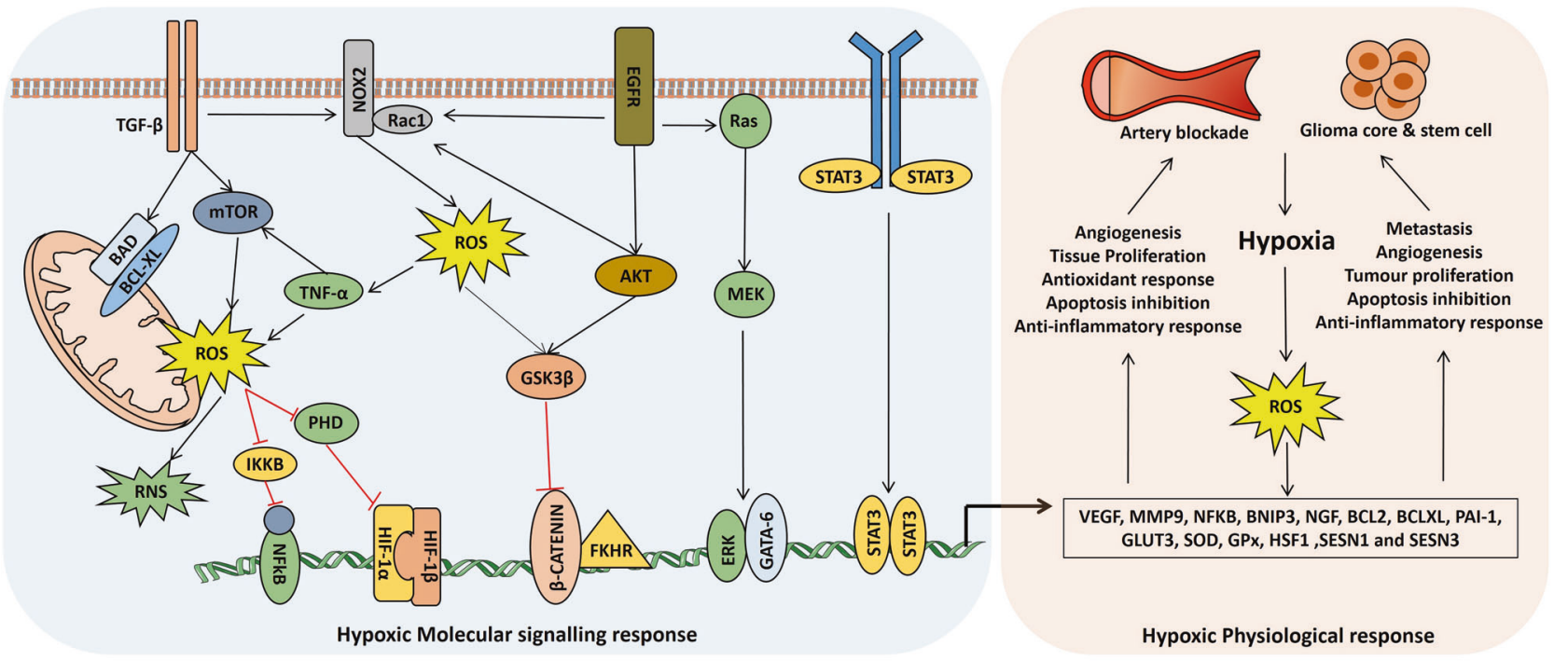

Fig. 2 Common hypoxic signaling pathways for cerebral ischemia and glioma 
active and produces a low amount of NO from neurons, but it kills the surrounding non-NOS-containing neurons. NO produced by endothelial NOS (eNOS) is a vasodilator and has neuroprotective properties. NO from the induced NOS (iNOS) is the main culprit for cerebral ischemic damage and kills the endothelium by 3-nitrotyrosine formation under oxygen and glucose deprivation. $^{99,100}$

\section{EFFECT OF ISCHEMIC ROS AND RNS ON GLIOMA}

Surprisingly, ROS and RNS have a dual role in the neurovascular unit, where they destroy tissues and macromolecules during the detrimental phase (global ischemia, reperfusion injuries) and aid in cell proliferation, tissue repair and regeneration and angiogenesis in the recovery phase (acute ischemic stroke, hypoxic tumor core, perivascular niche (PVN)). ${ }^{101}$ Moderately increased ROS are oncogenic while the highly increased level of ROS acts as a tumor suppressor. ${ }^{102}$ Therefore, cells bearing high levels of ROS are more susceptible to death, and the opposite is also true for the depleted ROS level in tumors. Furthermore, the level of cellular ROS is increased due to depletion of antioxidants and potentially contributes to the oxidative damage to biological macromolecules that leads to cytotoxic and mutagenic responses. ROS can contribute to genomic instability, thereby resulting in cell death or tumorigenesis. At the threshold level, ROS are recognized as intracellular signal transduction molecules that regulate kinasedriven pathways and mediate cellular responses to external stimuli. Additionally, ROS inhibit many phosphatases that negatively regulate signaling cascades, whereas an increased level of cellular ROS during oxidative stress creates an oxidant/antioxidant imbalance and is responsible for several malignancies. Based on the amount and potential, hypoxic ROS either aid in tumorigenesis and recurrence or cause massive tissue damage.

\section{ROS favor tumor growth}

The ROS-induced signaling pathways, viz. EGFR, MAP kinase, ${ }^{103,104}$ TGF $\beta^{60,105}$ and NF-kB, ${ }^{106,107}$ aid tumor development and progression as also participate in tissue repair, regeneration, and the healing processes in the postischemic recovery phase. ROS can also activate ERK1/2 signaling in glioma. ${ }^{108}$ RAS, an upstream activator of the ERK1/2 pathway, is also activated through oxidative modification by ROS at its cysteine 118 residue, which leads to inhibition of GTP/GDP exchange. ${ }^{109}$ Moreover, ROS can modulate pro-apoptotic factors such as $\mathrm{Bax}_{1}{ }^{110} \mathrm{Bad}, \mathrm{Bim}$, and FOXO family transcription factors. ${ }^{111}$ Tumor necrosis factor (TNF) and neuronal growth factor (NGF) display various functions from cell growth and differentiation to cell death. TNF-induced ROS can also activate antiapoptotic pathways due to activation of the transcription factor NF-KB. TGF $\beta$ is one of the major signaling pathways in both glioma and ischemia. ${ }^{112,113}$ In hypoxic ischemia, the elevated expression of cytokine-mediated TGF $\beta^{114}$ upregulates antiapoptotic $\mathrm{BCl} 2$ and $\mathrm{BCl}-\mathrm{xl}^{115}$ proteins and PAI-1 (ref. ${ }^{116}$ ) and also transactivates the MAPK pathway and offers neuroprotection from oxidative ischemic injuries. ${ }^{117}$ Moreover, in glioma, TGF $\beta$ increases ROS production and activates GSK3 $\beta$ via the mTOR pathway in mitochondria by suppressing antioxidant enzymes such as SOD and GPx. ${ }^{118}$

Another important pathway that acts on glioma and hypoxic ischemia in a similar manner is hypoxia-inducing factor 1 (HIF-1). HIF-1 is a heterodimeric protein with two subunits, viz. HIF-1a and HIF-1 $\beta$, that sense low oxygen tension in the tissue microenvironment and are upregulated due to the inhibition of degradation via PHD inactivation. ${ }^{119,120}$ HIF-1a upregulates the expression of glucose transporter 3 (GLUT3), ${ }^{12}$ VEGF, ${ }^{122}$ erythropoietin, ${ }^{123}$ and BNIP3 (ref. ${ }^{124}$ ) and suppresses cytochrome $c$ release, PARP cleavage, ${ }^{125,126}$ and p53 activation. ${ }^{127}$ Therefore, in one way, HIF-1 confers cell survival and in other way, it drives angiogenesis.
ROS are detrimental for tumor growth

Mitochondria are ROS generators that also increase the level of ROS which causes mitochondrial dysfunction. ${ }^{128,129}$ ROS also have great detrimental effects. A high level of ROS promotes severe cellular damage and even cell death. ROS are derived from endogenous and exogenous sources in ischemic stroke as a result of oxidative stress after a stroke, which leads to lipid peroxidation, DNA damage, protein degradation, and apoptosis. Apoptosis can be induced by both intracellular and extracellular signals through two major pathways, namely, the mitochondrial (intrinsic) and death receptor-mediated (extrinsic) pathways. ${ }^{130}$ The intrinsic apoptotic cascade associated with changes in the permeability of the outer mitochondrial membrane and ROS directly trigger this pathway by interacting with the pathway molecules. ${ }^{131}$ ROS induce pro-apoptotic molecules such as p53 and p38 kinases and increase cellular apoptosis. ${ }^{132}$ The truncated form of Bid proteins causes Bax/Bak oligomerization and creates megapores in mitochondria through the direct involvement of ROS, and an apoptosome complex is subsequently formed in the cytosol by activating caspase 9 and 3 to initiate apoptosis. ${ }^{133}$ Apoptosome complex is regulated and influenced by ROS in various contexts. In oxidative stress, excessive ROS are produced that damage biological macromolecules, viz. proteins, lipids, and DNA, creating fatal conditions in tissue cells that contribute to many diseases, including cancer. Increased expression of the Fas receptor or triggering of the mitochondrial permeability transition with the release of ROS is the basic mechanism of apoptosis induction in tumor cells. ${ }^{134,135}$ Intracellular ROS accumulation obstructs cellular proliferation and induces cell cycle arrest at the G1 and G2/M phases. ${ }^{136,137}$ Abnormally increased levels of ischemic ROS can selectively kill malignant cells and act as an adverse factor in causing genetic instability. Thus, enhanced ROS production in the tumor bed might be one of the important strategies in ROSmediated cancer therapy.

\section{ROLE OF NEUROVASCULAR UNIT IN ISCHEMIA AND GLIOMA}

\section{Astrocytes}

Astrocytes are the star-shaped and most abundant housekeeping non-neuronal cells found in the brain microenvironment. These cells form the blood-brain barrier (BBB) and tripartite synapses, help neurons and glial cells by supplying nutrition and other factors from the vasculature, and also maintain communication between the cells and the microenvironment. ${ }^{138}$

In cerebral ischemia, due to oxygen-glucose deprivation, dramatic changes (such as swelling, cytoplasmic hypertrophy, accumulation of GFAP, Vimentin, and other intermediate glial filaments) occur in astrocytes and increases of cellular organelles like mitochondria, ribosomes, nuclear size, and Golgi complexes leads to a metabolically activated reactive form. ${ }^{139}$ A meshwork of the cytoplasmic processes of activated astroglial cells form a glial scar around the area of the ischemic lesions. ${ }^{32,140}$ This activation process and subsequent mutational events of several genes, such as neurofibromatosis type $1(\mathrm{NF} 1)^{141-143}$ and glycoprotein podoplanin (PDPN), ${ }^{144}$ in reactive gliosis lead to gliomagenesis because both glial progenitor and reactive astrocyte cells are proposed origins of the same lineages. ${ }^{145-147}$ Astrocytic STAT3 increases MMP2 expression and inhibits RhoA and PTEN via miR21, which leads to adhesion turnover, actomyosin tonus, and migration of reactive astrocytes to form a glial scar. ${ }^{148,149}$ These reactive astrocytes enhance uncontrolled proliferation and migration of glioma cells by expressing MMPs $^{150}$ and secretory SDF1. ${ }^{151-153}$ The direct interaction between reactive astrocytes and glioma cells by tunneling nanotubes (TNT) and the secretion of IL6, IL19, IGF1, TGF $\beta$, MCP4, VEGF, etc. aid glioma cells in infiltrating the surrounding parenchyma. ${ }^{154-156}$ The expression of connexin $43(\mathrm{C} \times 43)^{157}$ and different ATP-dependent ion channels (CIC-3, VGCC, TRPs, hERG, ENaC, CLICs) ${ }^{158}$ in reactive astrocytes 
offer protection against radio- and chemotherapy via activation of $\mathrm{Bcl} 2$ family proteins and inhibition of cytochrome $c$ release from mitochondria. ${ }^{159}$ It is also reported that reactive astrocytes supply a suitable microenvironment for the transformation of $\mathrm{CD}_{133^{+}}$ glioma stem cells from $\mathrm{CD}_{133^{-}}$cells. ${ }^{153}$ Interestingly, the astrocyte's glycogen stores and the presence of a high amount of metallothionein (MT), glutathione, and other antioxidants protect the surrounding tissues from hypoglycemic and hypoxic ischemic shock. ${ }^{160-162}$

\section{Microglia}

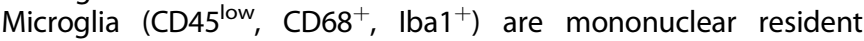
phagocytic macrophages of normal brain originated from myeloid stem cells in the yolk sac. ${ }^{163,164}$ The main functions of microglia are to offer immune protection of the brain, a clean brain microenvironment via phagocytosis of unwanted debris, support of other glial cells and neurons, and aid in BBB and synaptic plasticity maintenance. ${ }^{165,166}$ Microglia are one of the major sources of ROS, pro-, and anti-inflammatory cytokines, neurotropic and growth factors and act as the first line barrier of innate immunity by expressing pattern recognition receptors (TLRs, NLRs, and RLRs) for pathogen-associated molecular patterns and danger-associated molecular patterns (DAMPs) recognition. ${ }^{167-169}$ Microglia are involved in several cell signaling networks, e.g., NF-KB, TNFa, TGF $\beta$, interleukin signaling (IL1 $\beta$, IL6, IL4, and IL10), chemokine receptor signaling (CX3CL1/CX3CR1 and CCL2/CCR2), neurotransmitter signaling, and most importantly TREM2 signaling. ${ }^{170-173}$

Upon ischemic injuries, resident microglia together with monocyte-derived microglia [infiltrating from circulation to the brain tissue via ruptured BBB] become activated to various reactive forms. Interestingly, different classes of these reactive forms act in opposite manners to each other according to the situation. Due to breakdown of glia-neuron communication (CX3CL1/CX3CR1) and several excitotoxic signals such as DAMPs, purinergic signals and acute inflammatory environment resident microglia are transformed into three distinct morphological types, viz. enlarged cell body with low ramifications, amoeboid structure with rare ramifications, and a round-shaped highly activated form distributed from the peri-infarct regions into the core ischemic lesions. ${ }^{168,174-176}$ Despite the morphology, microglia are polarized into two distinct functional phenotypic variants, i.e., proinflammatory M1 and anti-inflammatory M2 forms (further divided into $\mathrm{M} 2 \mathrm{a}$ capable of repair, immunoregulatory $\mathrm{M} 2 \mathrm{~b}$, and immunomodulatory M2c). The classical M1 (CD16 ${ }^{+}, \mathrm{CD}^{2} 6^{+}, \mathrm{Fc} \mathrm{R}^{+}$, iNOS $^{+}$) phenotype secretes excessive amounts of ROS, RNS, TNFa, IL6, and IL1 $\beta$ for inflammatory response, cytotoxicity, and brain tissue damage. Alternatively, $\mathrm{M} 2\left(\mathrm{Arg}^{+}{ }^{+}, \mathrm{CD} 36^{+}, \mathrm{CD} 206^{+}, \mathrm{Ym}^{+}\right.$) phenotypes, mostly found in the ischemic core region, secrete IL4, IL10, and IL13 and TGF $\beta$, IGF1, NGF, and BDNF for neuroprotection, inhibition of apoptosis and necrosis, tissue and ECM repair and cleanup of debris via phagocytosis. ${ }^{177-180}$ Transformation of these microglia from M1 (tumor suppressive) to M2 (tumor promoting) form initiates immune suppression in the tumor area and also promotes tumor expansion, metastasis, angiogenesis, and glioma stem cell maintenance via the secretion of several factors (viz. MMPs, CCL18, CCL22, CXCL12, IL10, TGFB, TNF, FasL, VEGF). ${ }^{181-185}$

\section{Pericytes}

Pericytes $\left(\mathrm{PDGFR}^{+}, \mathrm{CD} 13^{+}, \mathrm{NG}^{+}, a-\mathrm{SMA}^{+}\right.$, Desmin $^{+}$) or Rouget cells are contractile cells located directly on small blood vessels, including capillaries, pre-capillary arterioles, and postcapillary venules. ${ }^{186}$ The major functions of pericytes are formation of blood vessels, glial scars, and the BBB, capillary diameter, and cerebral blood flow (CBF) regulation, amyloid $\beta$ clearance, and neuroinflammation suppression, and they at times exhibit stem cell-like properties. ${ }^{187}$

In acute focal cerebral ischemia, the "no-reflow phenomenon" and secondary hypoperfusion occur due to structural changes of the ischemic capillary bed because of astrocytic endfeet and endothelial swelling and constrictions of the capillary pericytes. $^{188,189}$ Several pathways, especially ROS-mediated translocation of myosin, thromboxane A2 release, and cytosolic calcium increase, cause pericytes constriction and death after ischemic stroke. ${ }^{190}$ However, ischemic hypoxia results in activation of A2a receptors, and the NO/guanylate cyclase pathway leads to the dilation of pericytes. ${ }^{191}$ Interestingly, pericytic ICAM-1 guides leukocyte migration through gaps between adjacent pericytes during ischemia. ${ }^{191,192}$ Due to induction of TNF-a in the ischemic region, RGS5-expressing pericytes take on an amoeboid morphology, detach from the basal lamina, and migrate toward the ischemic lesion via secretion of MMP9. ${ }^{193-195}$ It is also reported that the phagocytic behavior of pericytes increases during ischemic insults. Pericytes express a variety of neurotropic and neuroprotective factors such as GDNF, BDNF, NGF, and NT-3 that facilitate neuronal and axonal regeneration. ${ }^{196,197}$ Pericytes express Ang1 and GDNF, which maintain and enhance the tight junctions of endothelial cells by up-regulating claudin-5. ${ }^{198,199}$ Pericytes increase angiogenesis via the interactions of VEGF and FLT $1,{ }^{200}$ Ang 1 and Tie $2,{ }^{201}$ and PDGFR- $\beta$ and TGF- $\beta 1 .{ }^{202,203}$ Several reports exist on the reprogramming of pericytes into neurons $\left(\mathrm{NG} 2\right.$, sox2, and ascl1) ${ }^{204,205}$ and other glial ( $\mathrm{Iba}^{+}{ }^{+}, \mathrm{Glast}^{+}$) cells and formation of a glial scar due to the induction of a lineagespecific stem cell marker in ischemic conditions. ${ }^{206,207}$ These active pericytes aid in immune suppression, remodeling of PVN, and protection of glioma stem cells (GSC) or glioma-initiating cells (GICs) from ischemic injuries. ${ }^{208,209}$ Additionally, GSC recruits vascular pericytes via SDF1/CXCR4 signaling for angiogenesis. ${ }^{210,211}$ GICs maintain self-renewal and differential properties by interacting with pericyte-derived endothelial cells via PDGFNOS2-ID4 signaling. ${ }^{212,213}$

\section{Glioma stem cells}

GSCs and glioma-associated stem cells (GASC) are two types of cancer stem cells (CSCs) found in the glioma microenvironment. $^{214,215}$ Both cell populations have enhanced self-renewal and differential proliferation properties, but only GSCs can initiate tumor formation and proliferation. GSCs are heterogeneous in origin, are found in the inner core of the tumor mass, express several markers (SOX2, NANOG, BMI1, OLIG2, MUSASHI1, and CD133), and are resistant against chemo- and radiotherapy. ${ }^{216,217}$ These cells interact with the surrounding microenvironment, regulating multiple signaling networks such as VEGF, NF-kB, EGFR, HIF1a, TGF $\beta$, BMP, and NOTCH for promotion of tumor growth, metastasis and angiogenesis. ${ }^{218}$ In contrast, GASC are nontumorigenic tumor supporting stem cells originated from mesenchymal stem cells mostly found in the perivascular area. GASCs are classified into two categories according to their marker profile and functions. A high rate of proliferation of CD90 high GASC and secretion of exosomes loaded with growth factors, IL10, miRNA, CCL5, SDF-1a, and MMP9 support glioma proliferation and infiltration, whereas CD90 ${ }^{\text {low }}$ GASC produces VEGF, IL6, and FGF and is transformed into $\mathrm{CD} 31^{+}$from $\mathrm{CD}_{13}^{-}$pericytes for angiogenesis. ${ }^{219-221}$ A major hallmark of glioblastoma is the presence of ischemic pseudo-palisading necrosis, where chromodomain helicase DNA-binding protein 7 (CHD7) is expressed in an ischemic hypoxia-dependent manner and regulates angiogenesis. $^{35}$ GSCs produce NO via overexpression of nitric oxide synthase-2 (NOS2) in an ischemic condition, which aids in hyperproliferation. ${ }^{222}$

\section{Blood-brain barrier}

BBB is a highly selective physical barrier that regulates direct and indirect diffusion of molecules from circulation into the brain. The BBB consists of a nonfenestrated endothelial cell monolayer of blood capillaries connected by tight junctions and a basement membrane composed of specialized ECM, astrocyte endfeet, 
pericytes, neurons, and microglia. ${ }^{223,224}$ In hypoxic acute ischemia or high-grade glioma, a high rate of metabolism requires a high oxygen and nutrient supply such that expression of VEGF and PDGF increases, leading to angiogenesis. ${ }^{225,226}$ Increased vascularization together with the altered BBB forms the blood-brain tumor barrier (BBTB) or blood tumor barrier (BTB) with three distinct types of blood capillaries, viz. nonfenestrated continuous normal brain capillaries, continuous and partially fenestrated capillaries, and capillaries composed of inter-endothelial gaps and fenestration. ${ }^{227}$ Altered aquaporin expression and displacement of astrocyte endfeet, ${ }^{228}$ depletion of normal pericytes and recruitment of GSC derived pericytes, ${ }^{229}$ bradykinin-dependent migration of glioma cells toward capillaries, ${ }^{230}$ and finally, degradation of tight junction proteins of endothelial cells alter the BBTB structure and make it leaky, which causes rapid metastasis. ${ }^{231}$ Interestingly, the transmembrane proteins, e.g., ABC transporter, HB-EGF, PTGS2, ST6GALNAC5, and other drug efflux transporters, are also found in the BBTB, which supports chemo-resistance. ${ }^{232-235}$ Another important component of the glioma microenvironment is the PVN at the border area of the tumor and vasculature and is enriched with GSCs. $^{236}$ Several noncancerous cells such as macrophage, pericytes, astrocytes, and endothelial cells give support to GSCs for maintenance and proliferation in this region and maintain an immunosuppressive hypoxic environment. Signaling crosstalk between these cells in PVN makes this region radiotherapy- and chemotherapy resistant. $237-239$

\section{GLIOMA LEADS TO ISCHEMIC STROKE AND BRAIN INJURIES}

In glioma, the highly proliferating cell mass, metastasis, BBB breakdown and release of micro- and macroparticles in circulation cause thrombosis and capillary blockade, resulting in the focal ischemic condition. ${ }^{240,241}$ Blood vessel compression due to brain tumor formation also results in cerebral ischemia, which leads to a limited supply of nutrients to the brain that is unable to meet the metabolic demands of the brain tissue. Tumors in the brain progress gradually with time, whereas stroke occurs due to a certain blockage of blood in the brain. ${ }^{242} \mathrm{~A}$ recent patient cohortbased study on extracellular vesicles shows high correlation with D-dimer levels and cancer, which indicates increased risk of stroke in cancer patients. ${ }^{24,244}$ It is well established that glioma cells release factor $X$, mucins, ${ }^{245}$ podoplanin, ${ }^{246,247}$ and other procoagulant factors and cytokines ${ }^{248}$ that activate monocytes, endothelial cells, and platelets and also stimulate neutrophils to form neutrophil extracellular traps and inhibit protein $C$ activation, leading to local inflammation and ischemic hypoxia. ${ }^{249}$ Several reports showed that glioma therapy, especially platinum-based drugs, angiogenesis inhibitors, monoclonal antibodies, and radiotherapy, increased the risk of thromboembolism.
The characteristics of cancer-related stroke are completely different from those of conventional stroke. Hemorrhagic stroke can cause direct adverse effects on the tumor within the cranial vault. ${ }^{250,251}$ The intravascular coagulopathy that causes embolism is the main mechanism of cancer-related stroke. ${ }^{252,253}$ Direct effects either from tumor compression or from tumor embolism are another causal mechanism of stroke. Tumor bed edema leads to ischemia or infarction in the territory of the affected vessels and is clinically different from tumor progression. ${ }^{254}$ This mechanism is unique in that radiation treatment on the brain tumor might result in a stroke in certain cases. Selected chemotherapeutic agents (viz. cisplatin, methotrexate, L-asparaginase) ${ }^{255,256}$ and antiangiogenic agents (viz. paclitaxel, angiostatin) ${ }^{257-259}$ have also been associated with cerebral stroke. For example, the treatment of GBM with Bevacizumab shows a stroke rate of $1.9 \% .^{260-262}$ (Fig. 3).

\section{THERAPEUTIC APPROACHES FOR ISCHEMIA AND GLIOMA}

After the onset of cerebral ischemia, oxidative stress plays a major role in neuro-inflammatory diseases. ${ }^{263,264}$ In the postischemic brain, free radicals are increased by redox reactions and express several pro-inflammatory genes by multiple transcription factors, such as NF-KB, and inhibit the cellular antioxidant system. ${ }^{265,266}$ This phenomenon introduces novel anticancer drug discovery in the line of antioxidant therapy and treatment strategy. Therefore, anticancer drugs drive intracellular ROS production to destroy malignant cells. ROS levels increased by so-called oxidation therapy trigger cell death via the apoptosis or necrosis process. ${ }^{267}$ Several flavonoids such as quercetin, ${ }^{268,269}$ catechins, ${ }^{270}$ baicalein, ${ }^{271}$ delphinidin, ${ }^{272}$ apigenin, luteolin, ${ }^{273}$ and proanthocyanins protect the glial cells from oxidative stress, excitotoxicity, neuroinflammation, and cellular stress, although the increased level of free radicals reduces the proliferation of cells and even induces their death. ${ }^{274-277}$ These compounds also protect the brains of normal and cancer patients from ischemia. Gallic acid, an anticancer agent, can cause toxic effects by targeting mitochondrial antioxidant enzymes but also has beneficial effects on recovery of ischemic injuries. ${ }^{278-280}$ Overexpression of the oncogenic variant EGFRvIll and suppression of VEGF signaling are also involved in ROS production and represent an opportunity for the development of a new therapeutic strategy. ${ }^{281,282}$ Cardamonin (a chalcon) shows effective anti-inflammatory and anticarcinogenic activity in many cancers. ${ }^{283,284}$ It is reported that inhibition of NF-KB pathway activation is involved in breaking cellular redox homeostasis and triggers ROS production and accumulation through the JNK-mitogen-activated protein kinase (MAPK) axis. ${ }^{285,286}$ Due to high specificity and the power to cross the BBB, exosome- and nanovesicle-mediated delivery ${ }^{287-289}$ of peptides, ${ }^{290-293}$ small molecules, miRNA, ${ }^{294-296}$ and other drugs in

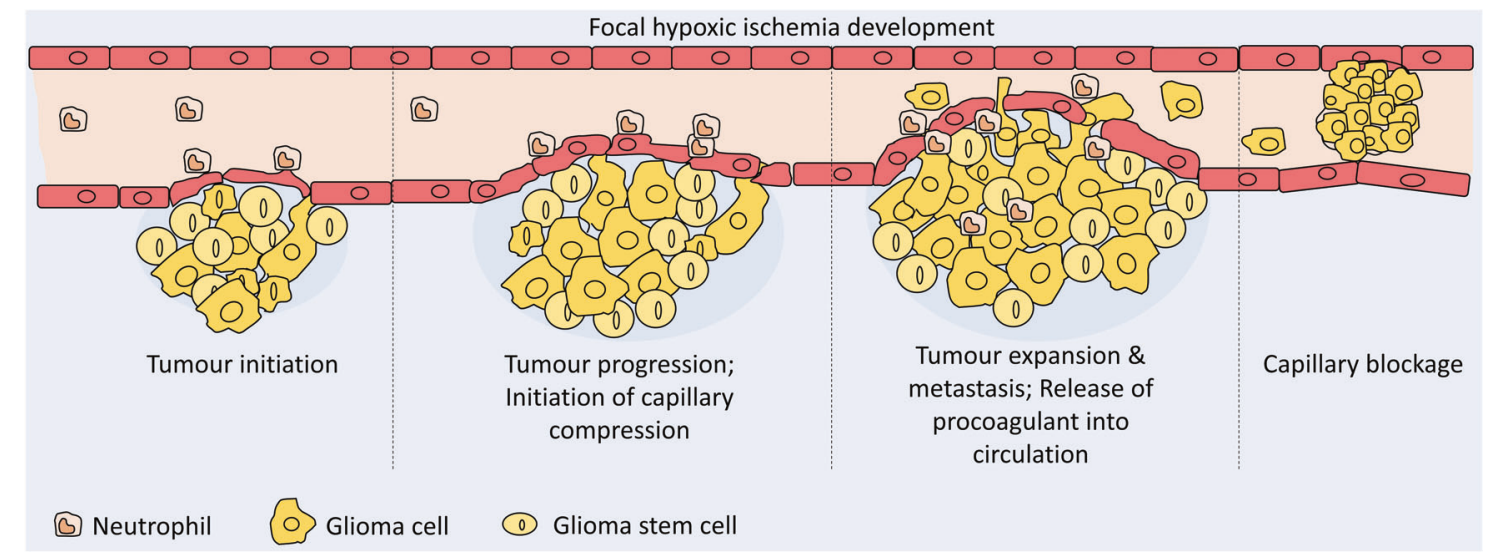

Fig. 3 Steps of focal cerebral ischemia development 


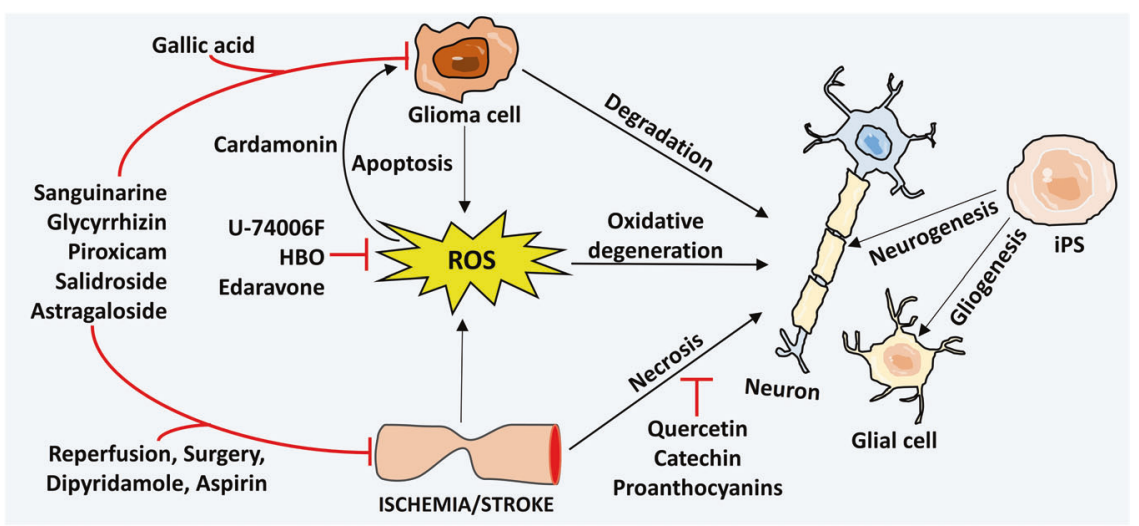

Fig. 4 Selected common therapeutic approaches applied for both glioma and cerebral ischemia

both glioma and cerebral ischemia therapy has gained recent successes.

Hyperbaric oxygen (HBO) therapy is a recently developed procedure in which oxygen is used under an elevated atmospheric pressure, i.e., at a pressure higher than the pressure found on the surface of the earth at sea level, which is defined as 1 atm. ${ }^{297}$ Currently, hyperbaric oxygenation is extensively used as an adjunctive treatment for various diseases predominantly related to hypoxic and/or ischemic conditions. Because ischemic stroke and brain cancer are also related to hypoxia, HBO therapy has distinct effects on these diseases. Because the hypoxic regions in the tumor mass play a major role in tumor development and resistance to novel radio- and chemotherapies, HBO therapy offers a promising approach to overcoming oxygen insufficiency by increasing the oxygen supply to neoplastic tissue. ${ }^{298-303}$ Recent results clearly suggest that $\mathrm{HBO}$ does not induce cancer growth, recurrence, or metastasis. However, $\mathrm{HBO}$ is observed to have an inhibitory effect on neoplastic cell proliferation and to cause cancer cell apoptosis. The beneficial effect of HBO therapy varies with the tumor type, size of the lesion, and malignancy. ${ }^{304-306}$

Several drugs, e.g., sanguinarine, ${ }^{307-309}$ glycyrrhizin, ${ }^{310}$ piroxi$\mathrm{cam}^{311-313}$ salidroside, ${ }^{314-316}$ astragaloside, ${ }^{317,318}$ and others, ${ }^{319-322}$ are used in both glioma and ischemia treatment due to the counteracting effect of common signaling pathways.

Out of basic clinical need, several studies have been conducted to examine the remedial capability of either endogenous or transplanted stem cells in laboratory models of cerebral ischemic stroke. Further bolstering their good advantages, stem cells show the ability to react effectively to their condition, move to the zones of injury, and discharge neuroprotective compounds, notwithstanding their ability to create an assortment of new functional cell types. ${ }^{323-325}$ Such properties might manage their restorative and therapeutic potential in both the acute stage and also at a later time after ordinary medicinal treatments are no longer viable. Reconstruction after stroke via stem cells is not likely within a reasonable time frame, and extraordinary care must be taken to guarantee security before considering clinical trials. Preliminary pieces of evidence underpin the remedial capability of certain stem cells for treatment of ischemic damage in animal models $s^{326-328}$ (Fig. 4).

\section{CONCLUDING REMARKS}

The mechanisms underlying the development of stroke in glioma patients are not yet clearly defined. Patients who suffer from both cancer and stroke are more difficult to treat than stroke patients who do not have cancer. The survival rate of glioma patients is increasing with the development of anticancer medicines, nanotherapeutics, and improved targeted nanodelivery systems that easily cross the BBB. Treating stroke in glioma patients can be challenging, requires specific treatment strategies, and has clinical and pathological consequences. The characteristics, type, extent, and time interval from diagnosis of cancer and stroke might be important in the development of stroke in patients with glioma.

\section{ACKNOWLEDGEMENTS}

This work was supported by grants received from DST (NanoMission: DST/NM/NT/ 2018/105(G) \& SR/NM/NS-1058/2015; and SERB: EMR/2017/000992/HS) Govt. of India.

\section{ADDITIONAL INFORMATION}

Conflict of interest:

The authors declare that they have no conflict of interest.

\section{REFERENCES}

1. Musuka, T. D., Wilton, S. B., Traboulsi, M. \& Hill, M. D. Diagnosis and management of acute ischemic stroke: speed is critical. CMAJ 187, 887-893 (2015).

2. KUNZ, A. \& IADECOLA, C. Cerebral vascular dysregulation in the ischemic brain. Handb. Clin. Neurol. 92, 283-305 (2009).

3. Smith, W. S. Pathophysiology of focal cerebral ischemia: a therapeutic perspective. J. Vasc. Interv. Radiol. 15, S3-S12 (2004).

4. Badimon, L. \& Vilahur, G. Platelets, arterial thrombosis and cerebral ischemia Cerebrovasc. Dis. 24(Suppl 1), 30-39 (2007).

5. Zhang, L. et al. Focal embolic cerebral ischemia in the rat. Nat. Protoc. 10, 539-547 (2015).

6. Neumann, J. T., Cohan, C. H., Dave, K. R., Wright, C. B. \& Perez-Pinzon, M. A. Global cerebral ischemia: synaptic and cognitive dysfunction. Curr. Drug Targets 14, 20-35 (2013).

7. Goodenberger, M. L. \& Jenkins, R. B. Genetics of adult glioma. Cancer Genet. 205, 613-621 (2012).

8. Louis, D. N. et al. The 2016 World Health Organization Classification of Tumors of the Central Nervous System: a summary. Acta Neuropathol. 131, 803-820 (2016).

9. KOMORI, T. Pathology and genetics of diffuse gliomas in adults. Neurol. Med. Chir. (Tokyo) 55, 28-37 (2015).

10. Bleeker, F. E., Molenaar, R. J. \& Leenstra, S. Recent advances in the molecular understanding of glioblastoma. J. Neurooncol. 108, 11-27 (2012).

11. Hadziahmetovic, M., Shirai, K. \& Chakravarti, A. Recent advancements in multimodality treatment of gliomas. Future Oncol. Lond. Engl. 7, 1169-1183 (2011).

12. Dützmann, S. et al. Risk of ischemia in glioma surgery: comparison of first and repeat procedures. J. Neurooncol. 107, 599-607 (2012).

13. Chen, C.-W. et al. Increased risk of brain cancer incidence in stroke patients: a clinical case series, population-based and longitudinal follow-up study. Oncotarget 8, 108989-108999 (2017).

14. Qureshi, A. I. et al. Incident cancer in a cohort of 3,247 cancer diagnosis free ischemic stroke patients. Cerebrovasc. Dis. 39, 262-268 (2015).

15. Wojtasiewicz, T. J., Ducruet, A. F., Noticewala, S. S., Canoll, P. \& McKhann, G. M. De novo glioblastoma in the territory of a prior middle cerebral artery infarct. Case Rep. Neurol. Med. 2013, 356526 (2013).

16. Pina, S. et al. Acute ischemic stroke secondary to glioblastoma. A case report. Neuroradiol. J. 27, 85-90 (2014). 
17. Talos, I.-F. et al. Supratentorial low-grade glioma resectability: statistical predictive analysis based on anatomic MR features and tumor characteristics. Radiology 239, 506-513 (2006).

18. Gempt, J. et al. Postoperative ischemic changes following resection of newly diagnosed and recurrent gliomas and their clinical relevance: Clinical article. J. Neurosurg. 118, 801-808 (2013).

19. Thiepold, A.-L. et al. Perioperative cerebral ischemia promote infiltrative recurrence in glioblastoma. Oncotarget 6, 14537-14544 (2015).

20. Krishnaiah, B. \& Ermak, D. Anaplastic astrocytoma presenting as ischemic stroke: a diagnostic pitfall. Austin J. Cerebrovasc. Dis. Stroke 4, 1058 (2017).

21. Yongqian, W., Qingqi, F., Jianyu, L., Zhengda, Z. \& Weiping, W. Acquired glioblastoma following prior middle cerebral artery infarct: case report and literature review. J. Neurol. Neurosurg. 3 (2016).

22. Bond, L. M. \& Skrobo, D. Multiple embolic cerebral infarcts as the first manifestation of metastatic ovarian cancer. BMJ Case Rep. 2015 (2015).

23. Farkas, A., Schlakman, B., Khan, M. \& Joyner, D. Glioblastoma presenting with acute middle cerebral artery territory infarct. J. Stroke Cerebrovasc. Dis. 27, e113-e114 (2018).

24. Lasocki, A. \& Gaillard, F. Ischaemic stroke in the setting of glioblastoma: a case series and review of the literature. Neuroradiol. J. 29, 155-159 (2016).

25. Amelot, A. et al. Glioblastoma complicated by fatal malignant acute ischemic stroke: MRI finding to assist in tricky surgical decision. Neuroradiol. J. 28, 483-487 (2015).

26. Menon, B., Vengamma, B., Suman, R. \& Reddy, K. Glioma masquerading as stroke. J. Indian Acad. Clin. Med. 11, 302-305 (2010).

27. Søndergaard, K. L., Hilton, D. A., Penney, M., Ollerenshaw, M. \& Demaine, A. G. Expression of hypoxia-inducible factor 1alpha in tumours of patients with glioblastoma. Neuropathol. Appl. Neurobiol. 28, 210-217 (2002).

28. Kasivisvanathan, V. et al. Hypoxia-inducible factor-1 in arterial disease: a putative therapeutic target. Curr. Vasc. Pharmacol. 9, 333-349 (2011).

29. Monteiro, A. R., Hill, R., Pilkington, G. J. \& Madureira, P. A. The role of hypoxia in glioblastoma invasion. Cells 6 (2017).

30. Becerra-Calixto, A. \& Cardona-Gómez, G. P. The role of astrocytes in neuroprotection after brain stroke: potential in cell therapy. Front. Mol. Neurosci. 10 (2017).

31. Molofsky, A. V. et al. Astrocytes and disease: a neurodevelopmental perspective. Genes Dev. 26, 891-907 (2012).

32. Huang, L. et al. Glial scar formation occurs in the human brain after ischemic stroke. Int. J. Med. Sci. 11, 344-348 (2014).

33. Villarreal, A. et al. Isolation and characterization of ischemia-derived astrocytes (IDAs) with ability to transactivate quiescent astrocytes. Front. Cell. Neurosci. 10 (2016).

34. Burda, J. E. \& Sofroniew, M. V. Reactive gliosis and the multicellular response to CNS damage and disease. Neuron 81, 229-248 (2014).

35. Boyd, N. H. et al. Chromodomain helicase DNA-binding protein 7 is suppressed in the perinecrotic/ischemic microenvironment and is a novel regulator of glioblastoma angiogenesis. Stem Cells 37, 453-462 (2019).

36. Kee, $\mathrm{H}$. J. et al. Expression of brain-specific angiogenesis inhibitor 3 (BAI3) in normal brain and implications for BAI3 in ischemia-induced brain angiogenesis and malignant glioma. FEBS Lett. 569, 307-316 (2004).

37. Teng, $\mathbf{H}$. et al. Coupling of angiogenesis and neurogenesis in cultured endothelial cells and neural progenitor cells after stroke. J. Cereb. Blood Flow. Metab. 28, 764-771 (2008).

38. The origin of circumscribed necroses and perinecrotic niches in glioblastoma multiforme: an additional hypothesis. Integr. Cancer Sci. Ther. 2 (2015).

39. Schiffer, D. et al. Glioblastoma stem cells: conversion or reprogramming from tumor non- stem cells? J. Stem Cell Res. Ther. 5 (2015)

40. Schiffer, D., Mellai, M., Annovazzi, L. \& Cassoni, C. C. and P. Tumor microenvironment-perivascular and perinecrotic niches. in Molecular Considerations and Evolving Surgical Management Issues in the Treatment of Patients with a Brain Tumo 5 (2015).

41. Ray, P. D., Huang, B.-W. \& Tsuji, Y. Reactive oxygen species (ROS) homeostasis and redox regulation in cellular signaling. Cell. Signal. 24, 981-990 (2012).

42. Chen, R. et al. Reactive oxygen species formation in the brain at different oxygen levels: the role of hypoxia inducible factors. Front. Cell Dev. Biol. 6 (2018).

43. Kwak, D. J., Kwak, S. D. \& Gauda, E. B. The effect of hyperoxia on reactive oxygen species (ROS) in rat petrosal ganglion neurons during development using organotypic slices. Pediatr. Res. 60, 371-376 (2006).

44. Kulkarni, A. C., Kuppusamy, P. \& Parinandi, N. Oxygen, the lead actor in the pathophysiologic drama: enactment of the trinity of normoxia, hypoxia, and hyperoxia in disease and therapy. Antioxid. Redox Signal. 9, 1717-1730 (2007).

45. Sumbayev, V. V. \& Yasinska, I. M. Mechanisms of hypoxic signal transduction regulated by reactive nitrogen species. Scand. J. Immunol. 65, 399-406 (2007)
46. Tan, S. et al. Sustained hypoxia-ischemia results in reactive nitrogen and oxygen species production and injury in the premature fetal rabbit brain. J. Neuropathol. Exp. Neurol. 57, 544-553 (1998).

47. Chen, X., Chen, H., Xu, M. \& Shen, J. Targeting reactive nitrogen species: a promising therapeutic strategy for cerebral ischemia-reperfusion injury. Acta Pharmacol. Sin. 34, 67-77 (2013).

48. Handy, D. E. \& Loscalzo, J. Redox regulation of mitochondrial function. Antioxid. Redox Signal. 16, 1323-1367 (2012).

49. Yang, J.-L., Mukda, S. \& Chen, S.-D. Diverse roles of mitochondria in ischemic stroke. Redox Biol. 16, 263-275 (2018).

50. Zorov, D. B., Juhaszova, M. \& Sollott, S. J. Mitochondrial reactive oxygen species (ROS) and ROS-induced ROS release. Physiol. Rev. 94, 909-950 (2014).

51. Doll, D. N., Rellick, S. L., Barr, T. L., Ren, X. \& Simpkins, J. W. Rapid mitochondrial dysfunction mediates TNF-alpha-induced neurotoxicity. J. Neurochem. 132, 443-451 (2015).

52. Sarafian, T. A. et al. Disruption of astrocyte STAT3 signaling decreases mitochondrial function and increases oxidative stress in vitro. PLOS ONE 5 (2010).

53. Nissanka, N. \& Moraes, C. T. Mitochondrial DNA damage and reactive oxygen species in neurodegenerative disease. FEBS Lett. 592, 728-742 (2018).

54. Cha, M.-Y., Kim, D. K. \& Mook-Jung, I. The role of mitochondrial DNA mutation on neurodegenerative diseases. Exp. Mol. Med. 47, e150 (2015).

55. Silva, T. M. D., Brait, V. H., Drummond, G. R., Sobey, C. G. \& Miller, A. A. Nox2 oxidase activity accounts for the oxidative stress and vasomotor dysfunction in mouse cerebral arteries following ischemic stroke. PLOS ONE 6, e28393 (2011).

56. Kahles, T. \& Brandes, R. P. Which NADPH oxidase isoform is relevant for ischemic stroke? The case for Nox 2. Antioxid. Redox Signal. 18, 1400-1417 (2013).

57. Kim, J. Y., Park, J., Lee, J. E. \& Yenari, M. A. NOX inhibitors-a promising avenue for ischemic stroke. Exp. Neurobiol. 26, 195-205 (2017).

58. Hsieh, C.-H. et al. NADPH oxidase subunit 4-mediated reactive oxygen species contribute to cycling hypoxia-promoted tumor progression in glioblastoma multiforme. PLOS ONE 6, e23945 (2011).

59. Zhang, L. et al. NADPH oxidase: a potential target for treatment of stroke. Oxid. Med. Cell. Longev. 2016, 5026984 (2016).

60. Lou, Z. et al. Upregulation of NOX 2 and NOX4 mediated by TGF- $\beta$ signaling pathway exacerbates cerebral ischemia/reperfusion oxidative stress injury. Cell. Physiol. Biochem. 46, 2103-2113 (2018).

61. Nakanishi, A., Wada, Y., Kitagishi, Y. \& Matsuda, S. Link between PI3K/AKT/PTEN pathway and NOX proteinin diseases. Aging Dis. 5, 203-211 (2014).

62. Cai, L. et al. Combining normobaric oxygen with ethanol or hypothermia prevents brain damage from thromboembolic stroke via PKC-Akt-NOX modulation. Mol. Neurobiol. 54, 1263-1277 (2017).

63. Rastogi, R., Geng, X., Li, F. \& Ding, Y. NOX activation by subunit interaction and underlying mechanisms in disease. Front. Cell. Neurosci. 10 (2017).

64. Schrader, M. \& Fahimi, H. D. Peroxisomes and oxidative stress. Biochim. Biophys. Acta 1763, 1755-1766 (2006).

65. del Río, L. A. et al. Reactive oxygen species, antioxidant systems and nitric oxide in peroxisomes. J. Exp. Bot. 53, 1255-1272 (2002).

66. Bonekamp, N. A., Völkl, A., Fahimi, H. D. \& Schrader, M. Reactive oxygen species and peroxisomes: struggling for balance. BioFactors Oxf. Engl. 35, 346-355 (2009).

67. Fransen, M., Nordgren, M., Wang, B. \& Apanasets, O. Role of peroxisomes in ROS/ RNS-metabolism: implications for human disease. Biochim. Biophys. Acta 1822, 1363-1373 (2012).

68. Battelli, M. G., Polito, L., Bortolotti, M. \& Bolognesi, A. Xanthine oxidoreductasederived reactive species: physiological and pathological effects. Oxid. Med. Cell Longev. 548, 1-8 (2016).

69. Hippeli, S. \& Elstner, E. F. Transition metal ion-catalyzed oxygen activation during pathogenic processes. FEBS Lett. 443, 1-7 (1999).

70. SUZUKI, G. et al. Evaluation of neuronal protective effects of xanthine oxidoreductase inhibitors on severe whole-brain ischemia in mouse model and analysis of xanthine oxidoreductase activity in the mouse brain. Neurol. Med. Chir. (Tokyo) 55, 77-85 (2015).

71. Griguer, C. E. et al. Xanthine oxidase-dependent regulation of hypoxia-inducible factor in cancer cells. Cancer Res. 66, 2257-2263 (2006).

72. Ben-Mahdi, M. H. et al. Xanthine oxidase-derived ROS display a biphasic effect on endothelial cells adhesion and FAK phosphorylation. Oxid. Med. Cell. Longev. 5, 1-9 (2016)

73. Hrycay, E. G. \& Bandiera, S. M. Involvement of cytochrome P450 in reactive oxygen species formation and cancer. Adv. Pharmacol. 74, 35-84 (2015).

74. Zangar, R. C., Davydov, D. R. \& Verma, S. Mechanisms that regulate production of reactive oxygen species by cytochrome P450. Toxicol. Appl. Pharmacol. 199, 316-331 (2004).

75. $\mathrm{Li}$, R. et al. Cytochrome P450 $2 \mathrm{~J} 2$ is protective against global cerebral ischemia in transgenic mice. Prostaglandins Other Lipid Mediat. 99, 68-78 (2012). 
76. Ghosh, C. et al. Pathophysiological implications of neurovascular P450 in brain disorders. Drug Discov. Today 21, 1609-1619 (2016).

77. Alkayed Nabil, J. et al. Neuroprotection and P450 2C11 upregulation after experimental transient ischemic attack. Stroke 33, 1677-1684 (2002).

78. Han, S. et al. Lysyl oxidase genetic variants and the prognosis of glioma. APMIS 122, 200-205 (2014).

79. Huang, S.-P. et al. Over-expression of lysyl oxidase is associated with poor prognosis and response to therapy of patients with lower grade gliomas. Biochem. Biophys. Res. Commun. 501, 619-627 (2018).

80. Zhang, H.-F. et al. Lysyl oxidase polymorphisms and ischemic stroke-a case control study. Mol. Biol. Rep. 39, 9391-9397 (2012).

81. Matsuura, S. et al. Lysyl oxidase is associated with increased thrombosis and platelet reactivity. Blood 127, 1493-1501 (2016).

82. Martínez-Revelles, S. et al. Lysyl oxidase induces vascular oxidative stress and contributes to arterial stiffness and abnormal elastin structure in hypertension: role of p38MAPK. Antioxid. Redox Signal. 27, 379-397 (2017).

83. Adachi, Y. et al. Oncogenic Ras upregulates NADPH oxidase 1 gene expression through MEK-ERK-dependent phosphorylation of GATA-6. Oncogene 27, 4921-4932 (2008).

84. Valente, A. J. et al. Regulation of NOX1 expression by GATA, HNF-1alpha, and Cdx transcription factors. Free Radic. Biol. Med. 44, 430-443 (2008).

85. Zamkova, M., Khromova, N., Kopnin, B. P. \& Kopnin, P. Ras-induced ROS upregulation affecting cell proliferation is connected with cell type-specific alterations of HSF1/SESN3/p21Cip1/WAF1 pathways. Cell Cycle 12, 826-836 (2013).

86. Byun, H.-O. et al. GSK3 inactivation is involved in mitochondrial complex IV defect in transforming growth factor (TGF) $\beta 1$-induced senescence. Exp. Cell Res. 318, 1808-1819 (2012).

87. Jain, $M$. et al. Mitochondrial reactive oxygen species regulate transforming growth factor- $\beta$ signaling. J. Biol. Chem. 288, 770-777 (2013).

88. Chandel, N. S., Trzyna, W. C., McClintock, D. S. \& Schumacker, P. T. Role of oxidants in NF-KB activation and TNF-a gene transcription induced by hypoxia and endotoxin. J. Immunol. 165, 1013-1021 (2000).

89. Blaser, H., Dostert, C., Mak, T. W. \& Brenner, D. TNF and ROS crosstalk in inflammation. Trends Cell Biol. 26, 249-261 (2016).

90. Edmunds, L. R. et al. c-Myc and AMPK control cellular energy levels by cooperatively regulating mitochondrial structure and function. PLOS ONE 10, e0134049 (2015).

91. Lee, S. B. et al. Romo1 is a negative-feedback regulator of Myc. J. Cell Sci. 124, 1911-1924 (2011).

92. Graves, J. A., Metukuri, M., Scott, D., Rothermund, K. \& Prochownik, E. V. Regulation of reactive oxygen species homeostasis by peroxiredoxins and c-Myc. J. Biol. Chem. 284, 6520-6529 (2009).

93. García-González, V. \& Mas-Oliva, J. A novel $\beta$-adaptin/c-Myc complex formation modulated by oxidative stress in the control of the cell cycle in macrophages and its implication in atherogenesis. Sci. Rep. 7, 13442 (2017).

94. Kim, J. H. et al. Activation of the PI3K/mTOR pathway by BCR-ABL contributes to increased production of reactive oxygen species. Blood 105, 1717-1723 (2005).

95. Breggia, A. C., Wojchowski, D. M. \& Himmelfarb, J. JAK2/Y343/STAT5 signaling axis is required for erythropoietin-mediated protection against ischemic injury in primary renal tubular epithelial cells. Am. J. Physiol. Ren. Physiol. 295, F1689-F1695 (2008)

96. Förstermann, U. \& Sessa, W. C. Nitric oxide synthases: regulation and function. Eur. Heart J. 33, 829-837 (2012).

97. Ito, Y. et al. Nitric oxide production during cerebral ischemia and reperfusion in eNOS- and nNOS-knockout mice. Curr. Neurovasc. Res. 7, 23-31 (2010).

98. Fukuyama, N. et al. Peroxynitrite formation in focal cerebral ischemiareperfusion in rats occurs predominantly in the peri-infarct region. J. Cereb. Blood Flow. Metab. 18, 123-129 (1998).

99. Santos, R. M., Lourenço, C. F., Ledo, A., Barbosa, R. M. \& Laranjinha, J. Nitric oxide inactivation mechanisms in the brain: role in bioenergetics and neurodegeneration. Int. J. Cell Biol. 4, 391914 (2012).

100. Xu Jan et al. Oxygen-glucose deprivation induces inducible nitric oxide synthase and nitrotyrosine expression in cerebral endothelial cells. Stroke 31, 1744-1751 (2000).

101. Kalogeris, T., Bao, Y. \& Korthuis, R. J. Mitochondrial reactive oxygen species: a double edged sword in ischemia/reperfusion vs preconditioning. Redox Biol. 2, 702-714 (2014)

102. Salazar-Ramiro, A. et al. Role of redox status in development of glioblastoma. Front. Immunol. 7 (2016)

103. Zhou, J. et al. Crosstalk between MAPK/ERK and PI3K/AKT signal pathways during brain ischemia/reperfusion. ASN Neuro 7 (2015).

104. Weng, M.-S., Chang, J.-H., Hung, W.-Y., Yang, Y.-C. \& Chien, M.-H. The interplay of reactive oxygen species and the epidermal growth factor receptor in tumor progression and drug resistance. J. Exp. Clin. Cancer Res. 37 (2018).
105. Roy, L.-O., Poirier, M.-B. \& Fortin, D. Differential expression and clinical significance of transforming growth factor-beta isoforms in GBM tumors. Int. J. Mol. Sci. 19 (2018).

106. Cahill, K. E., Morshed, R. A. \& Yamini, B. Nuclear factor-kB in glioblastoma: insights into regulators and targeted therapy. Neuro-Oncol. 18, 329-339 (2015).

107. Ridder, D. A. \& Schwaninger, M. NF-kappaB signaling in cerebral ischemia. Neuroscience 158, 995-1006 (2009).

108. Son, Y. et al. Mitogen-activated protein kinases and reactive oxygen species: how can ROS activate MAPK pathways? J.Signal Transduct. 792639 (2011).

109. Mitchell, L., Hobbs, G. A., Aghajanian, A. \& Campbell, S. L. Redox regulation of Ras and Rho GTPases: mechanism and function. Antioxid. Redox Signal. 18, 250-258 (2013).

110. Kirkland, R. A. \& Franklin, J. L. Bax, reactive oxygen, and cytochrome c release in neuronal apoptosis. Antioxid. Redox Signal. 5, 589-596 (2003).

111. Hagenbuchner, J. et al. FOXO3-induced reactive oxygen species are regulated by BCL2L11 (Bim) and SESN3. J. Cell Sci. 125, 1191-1203 (2012).

112. Pozniak, P. D., White, M. K. \& Khalili, K. TNF-a/NF-KB signaling in the CNS: possible connection to EPHB2. J. Neurolmmune Pharmacol. 9, 133-141 (2014).

113. Gloire, G., Legrand-Poels, S. \& Piette, J. NF-kappaB activation by reactive oxygen species: fifteen years later. Biochem. Pharmacol. 72, 1493-1505 (2006).

114. Pál, G., Lovas, G. \& Dobolyi, A. Induction of transforming growth factor beta receptors following focal ischemia in the rat brain. PLOS ONE 9, e106544 (2014).

115. Zhu, Y. et al. Transforming growth factor- $\beta 1$ increases Bad phosphorylation and protects neurons against damage. J. Neurosci. 22, 3898-3909 (2002).

116. Docagne, F. et al. Transforming growth factor-beta1 as a regulator of the serpins/t-PA axis in cerebral ischemia. FASEB J. 13, 1315-1324 (1999).

117. Dobolyi, A., Vincze, C., Pál, G. \& Lovas, G. The neuroprotective functions of transforming growth factor beta proteins. Int. J. Mol. Sci. 13, 8219-8258 (2012).

118. Krstić, J., Trivanović, D., Mojsilović, S. \& Santibanez, J. F. Transforming growth factor-beta and oxidative stress interplay: implications in tumorigenesis and cancer progression. Oxid. Med. Cell. Longev. 654594 (2015).

119. Sharp, F. R., Bergeron, M. \& Bernaudin, M. Hypoxia-inducible factor in brain. Adv. Exp. Med. Biol. 502, 273-291 (2001).

120. Singh, N., Sharma, G. \& Mishra, V. Hypoxia inducible factor-1: its potential role in cerebral ischemia. Cell. Mol. Neurobiol. 32, 491-507 (2012)

121. Liu, Y. et al. The expression and significance of HIF-1alpha and GLUT-3 in glioma. Brain Res. 1304, 149-154 (2009).

122. Kaur, B. et al. Hypoxia and the hypoxia-inducible-factor pathway in glioma growth and angiogenesis. Neuro-Oncology 7, 134-153 (2005).

123. Souvenir, R. et al. Erythropoietin inhibits HIF-1a expression via upregulation of PHD-2 transcription and translation in an in-vitro model of hypoxia ischemia. Transl. Stroke Res. 5, 118-127 (2014).

124. Sowter, H. M., Ratcliffe, P. J., Watson, P., Greenberg, A. H. \& Harris, A. L. HIF-1dependent regulation of hypoxic induction of the cell death factors BNIP3 and NIX in huuman tumors. Cancer Res. 61, 6669-6673 (2001).

125. Greijer, A. E. \& van der Wall, E. The role of hypoxia inducible factor 1 (HIF-1) in hypoxia induced apoptosis. J. Clin. Pathol. 57, 1009-1014 (2004).

126. Zhang, Q., Qian, Z., Pan, L., Li, H. \& Zhu, H. Hypoxia-inducible factor 1 mediates the anti-apoptosis of berberine in neurons during hypoxia/ischemia. Acta Physiol. Hung. 99, 311-323 (2012).

127. Chen, D., Li, M., Luo, J. \& Gu, W. Direct interactions between HIF-1a and Mdm2 modulate p53 function. J. Biol. Chem. 278, 13595-13598 (2003).

128. Ježek, J., Cooper, K. F. \& Strich, R. Reactive oxygen species and mitochondrial dynamics: the Yin and Yang of mitochondrial dysfunction and cancer progression. Antioxidants 7, 13 (2018).

129. Guo, C., Sun, L., Chen, X. \& Zhang, D. Oxidative stress, mitochondrial damage and neurodegenerative diseases. Neural Regen. Res. 8, 2003-2014 (2013).

130. Chen, $H$. et al. Oxidative stress in ischemic brain damage: mechanisms of cell death and potential molecular targets for neuroprotection. Antioxid. Redox Signal. 14, 1505-1517 (2011).

131. Niizuma, K. et al. Mitochondrial and apoptotic neuronal death signaling pathways in cerebral ischemia. Biochim. Biophys. Acta 1802, 92-99 (2010).

132. Wu, J. et al. Juglone induces apoptosis of tumor stem-like cells through ROS-p38 pathway in glioblastoma. BMC Neurol. 17, 70 (2017).

133. Plesnila, N. et al. BID mediates neuronal cell death after oxygen/glucose deprivation and focal cerebral ischemia. Proc. Natl Acad. Sci. USA 98, 15318-15323 (2001).

134. Wang, L. et al. The Fas death signaling pathway connecting reactive oxygen species generation and FLICE inhibitory protein down-regulation. J. Immunol. 180, 3072-3080 (2008).

135. Jayanthi, S., Lewis, B. D. \& Cadet, J. L. Fas-induced apoptosis of glioma cells is associated with down-regulation of the hSCO1 protein, a subunit of complex IV. Brain Res. Mol. Brain Res. 91, 131-136 (2001).

136. Lal, N., Nemaysh, V. \& Luthra, P. M. Proteasome mediated degradation of CDC25C and Cyclin B1 in demethoxycurcumin treated human glioma U87 MG 
cells to trigger G2/M cell cycle arrest. Toxicol. Appl. Pharmacol. 356, 76-89 (2018).

137. Shimada, K. et al. Copper-binding small molecule induces oxidative stress and cell-cycle arrest in glioblastoma-patient-derived cells. Cell Chem. Biol. 25, 585-594.e7 (2018).

138. Sofroniew, M. V. \& Vinters, H. V. Astrocytes: biology and pathology. Acta Neuropathol. 119, 7-35 (2010).

139. Panickar, K. S. \& Norenberg, M. D. Astrocytes in cerebral ischemic injury: morphological and general considerations. Glia 50, 287-298 (2005).

140. Sims, N. R. \& Yew, W. P. Reactive astrogliosis in stroke: contributions of astrocytes to recovery of neurological function. Neurochem. Int. 107, 88-103 (2017).

141. Zhu, Y. et al. Ablation of NF1 function in neurons induces abnormal development of cerebral cortex and reactive gliosis in the brain. Genes Dev. 15, 859-876 (2001)

142. Rizvi, T. A. et al. Region-specific astrogliosis in brains of mice heterozygous for mutations in the neurofibromatosis type 1 (Nf1) tumor suppressor. Brain Res. 816, 111-123 (1999).

143. Nordlund, M. L., Rizvi, T. A., Brannan, C. I. \& Ratner, N. Neurofibromin expression and astrogliosis in neurofibromatosis (type 1) brains. J. Neuropathol. Exp. Neurol. 54, 588-600 (1995)

144. Kolar, K. et al. Podoplanin: a marker for reactive gliosis in gliomas and brain injury. J. Neuropathol. Exp. Neurol. 74, 64-74 (2015).

145. Götz, M., Sirko, S., Beckers, J. \& Irmler, M. Reactive astrocytes as neural stem or progenitor cells: in vivo lineage, in vitro potential, and genome-wide expression analysis. Glia 63, 1452-1468 (2015).

146. Shimada, I. S., LeComte, M. D., Granger, J. C., Quinlan, N. J. \& Spees, J. L. Selfrenewal and differentiation of reactive astrocyte-derived neural stem/progenitor cells isolated from the cortical peri-infarct area after stroke. J. Neurosci. 32, 7926-7940 (2012).

147. Buffo, A. et al. Origin and progeny of reactive gliosis: a source of multipotent cells in the injured brain. Proc. Natl Acad. Sci. USA 105, 3581-3586 (2008).

148. Renault-Mihara, F. et al. Regulation of RhoA by STAT3 coordinates glial scar formation. J. Cell Biol. 216, 2533-2550 (2017).

149. Ou, H., Li, Y. \& Kang, M. Activation of miR-21 by STAT3 induces proliferation and suppresses apoptosis in nasopharyngeal carcinoma by targeting PTEN gene. PLOS ONE 9, e109929 (2014).

150. Le, D. M. et al. Exploitation of astrocytes by glioma cells to facilitate invasiveness: a mechanism involving matrix metalloproteinase- 2 and the urokinase-type plasminogen activator-plasmin cascade. J. Neurosci. 23, 4034-4043 (2003).

151. Tanabe, S. et al. Functional expression of the CXC-chemokine receptor-4/fusin on mouse microglial cells and astrocytes. J. Immunol. 159, 905-911 (1997).

152. Barbero, S. et al. Stromal cell-derived factor 1a stimulates human glioblastoma cell growth through the activation of both extracellular signal-regulated kinases $1 / 2$ and Akt. Cancer Res. 63, 1969-1974 (2003).

153. Rath, B. H., Fair, J. M., Jamal, M., Camphausen, K. \& Tofilon, P. J. Astrocytes enhance the invasion potential of glioblastoma stem-like cells. PLOS ONE $\mathbf{8}$, e54752 (2013).

154. Zhang, L. \& Zhang, Y. Tunneling nanotubes between rat primary astrocytes and C6 glioma cells alter proliferation potential of glioma cells. Neurosci. Bull. 31, 371-378 (2015)

155. Okolie, O. et al. Reactive astrocytes potentiate tumor aggressiveness in a murine glioma resection and recurrence model. Neuro-Oncology 18, 1622-1633 (2016).

156. Shabtay-Orbach, A., Amit, M., Binenbaum, Y., Na'ara, S. \& Gil, Z. Paracrine regulation of glioma cells invasion by astrocytes is mediated by glial-derived neurotrophic factor. Int. J. Cancer 137, 1012-1020 (2015).

157. Sin, W. C. et al. Astrocytes promote glioma invasion via the gap junction protein connexin43. Oncogene 35, 1504-1516 (2016).

158. Olsen, M. L. et al. New Insights on astrocyte ion channels: critical for homeostasis and neuron-glia signaling. J. Neurosci. 35, 13827-13835 (2015).

159. Lin, Q. et al. Astrocytes protect glioma cells from chemotherapy and upregulate survival genes via gap junctional communication. Mol. Med. Rep. 13, 1329-1335 (2016).

160. Hossain, M. I., Roulston, C. L. \& Stapleton, D. I. Molecular basis of impaired glycogen metabolism during ischemic stroke and hypoxia. PLOS ONE 9, e97570 (2014).

161. Neal, J. W., Singhrao, S. K., Jasani, B. \& Newman, G. R. Immunocytochemically detectable metallothionein is expressed by astrocytes in the ischaemic human brain. Neuropathol. Appl. Neurobiol. 22, 243-247 (1996).

162. Rossi, D. J., Brady, J. D. \& Mohr, C. Astrocyte metabolism and signaling during brain ischemia. Nat. Neurosci. 10, 1377-1386 (2007).

163. Tay, T. L., Savage, J. C., Hui, C. W., Bisht, K. \& Tremblay, M. Microglia across the lifespan: from origin to function in brain development, plasticity and cognition. J. Physiol. 595, 1929-1945 (2017).

164. Lannes, N., Eppler, E., Etemad, S., Yotovski, P. \& Filgueira, L. Microglia at center stage: a comprehensive review about the versatile and unique residential macrophages of the central nervous system. Oncotarget 8, 114393-114413 (2017).

165. von Bernhardi, R., Heredia, F., Salgado, N. \& Muñoz, P. Microglia function in the normal brain. Adv. Exp. Med. Biol. 949, 67-92 (2016).

166. Lenz, K. M. \& Nelson, L. H. Microglia and beyond: innate immune cells as regulators of brain development and behavioral function. Front. Immunol. 9 (2018).

167. Kofler, J. \& Wiley, C. A. Microglia: key innate immune cells of the brain. Toxicol. Pathol. 39, 103-114 (2011).

168. Gülke, E., Gelderblom, M. \& Magnus, T. Danger signals in stroke and their role on microglia activation after ischemia. Ther. Adv. Neurol. Disord. 11, 1756286418774254 (2018).

169. Yang, I., Han, S. J., Kaur, G., Crane, C. \& Parsa, A. T. The role of microglia in central nervous system immunity and glioma. Immunol. J. Clin. Neurosci. 17, 6-10 (2010).

170. Madry, C. \& Attwell, D. Receptors, ion channels, and signaling mechanisms underlying microglial dynamics. J. Biol. Chem. 290, 12443-12450 (2015).

171. ElAli, A. \& Rivest, S. Microglia ontology and signaling. Front. Cell Dev. Biol. 4 (2016).

172. Zhong, L. et al. TREM2/DAP12 complex regulates inflammatory responses in microglia via the JNK signaling pathway. Front. Aging Neurosci. 9, 204 (2017).

173. Hanisch, U.-K. Microglia as a source and target of cytokines. Glia 40, 140-155 (2002).

174. Taylor, R. A. \& Sansing, L. H. Microglial responses after ischemic stroke and intracerebral hemorrhage. Clin. Dev. Immunol. 746068 (2013).

175. Barakat, R. \& Redzic, Z. The role of activated microglia and resident macrophages in the neurovascular unit during cerebral ischemia: is the jury still out? Med. Princ. Pract. 25(Suppl 1), 3-14 (2016).

176. Zhao, S.-C. et al. Regulation of microglial activation in stroke. Acta Pharmacol. Sin. 38, 445-458 (2017)

177. Ma, Y., Wang, J., Wang, Y. \& Yang, G.-Y. The biphasic function of microglia in ischemic stroke. Prog. Neurobiol. 157, 247-272 (2017).

178. Patel, A. R., Ritzel, R., McCullough, L. D. \& Liu, F. Microglia and ischemic stroke: a double-edged sword. Int. J. Physiol. Pathophysiol. Pharmacol. 5, 73-90 (2013).

179. Guruswamy, R. \& EIAli, A. Complex roles of microglial cells in ischemic stroke pathobiology: new insights and future directions. Int. J. Mol. Sci. 18, E496 (2017).

180. Fumagalli, S., Perego, C., Pischiutta, F., Zanier, E. R. \& De Simoni, M.-G. The ischemic environment drives microglia and macrophage function. Front. Neurol. 6, 81 (2015).

181. Gabrusiewicz, K. et al. Characteristics of the alternative phenotype of microglia/ macrophages and its modulation in experimental gliomas. PIOS ONE 6, e23902 (2011).

182. Bryukhovetskiy, I. et al. Cancer stem cells and microglia in the processes of glioblastoma multiforme invasive growth. Oncol. Lett. 12, 1721-1728 (2016).

183. Ye, X. et al. Tumor-associated microglia/macrophages enhance the invasion of glioma stem-like cells via TGF- $\beta 1$ signaling pathway. J. Immunol. 189, 444-453 (2012).

184. Li, W. \& Graeber, M. B. The molecular profile of microglia under the influence of glioma. Neuro-Oncology 14, 958-978 (2012).

185. da Fonseca, A. C. C. \& Badie, B. Microglia and macrophages in malignant gliomas: recent discoveries and implications for promising therapies. Clin. Dev. Immunol. 2013, 264124 (2013).

186. Sweeney, M. D., Ayyadurai, S. \& Zlokovic, B. V. Pericytes of the neurovascular unit: key functions and signaling pathways. Nat. Neurosci. 19, 771-783 (2016).

187. Yemisci, M. et al. Pericyte contraction induced by oxidative-nitrative stress impairs capillary reflow despite successful opening of an occluded cerebral artery. Nat. Med. 15, 1031-1037 (2009).

188. Cai, W. et al. Pericytes in brain injury and repair after ischemic stroke. Transl. Stroke Res. 8, 107-121 (2017)

189. Fernández-Klett, F. \& Priller, J. Diverse functions of pericytes in cerebral blood flow regulation and ischemia. J. Cereb. Blood Flow. Metab. 35, 883-887 (2015).

190. Hamilton, N. B., Attwell, D. \& Hall, C. N. Pericyte-mediated regulation of capillary diameter: a component of neurovascular coupling in health and disease. Front. Neuroenergetics 2, 5 (2010).

191. Proebstl, D. et al. Pericytes support neutrophil subendothelial cell crawling and breaching of venular walls in vivo. J. Exp. Med. 209, 1219-1234 (2012).

192. Lyck, R. \& Enzmann, G. The physiological roles of ICAM-1 and ICAM-2 in neutrophil migration into tissues. Curr. Opin. Hematol. 22, 53-59 (2015).

193. Özen, I. et al. Brain pericytes acquire a microglial phenotype after stroke. Acta Neuropathol. 128, 381-396 (2014).

194. Sakuma, R. et al. Brain pericytes serve as microglia-generating multipotent vascular stem cells following ischemic stroke. J. Neuroinflammation 13, 57 (2016).

195. Underly, R. G. et al. Pericytes as inducers of rapid, matrix metalloproteinase-9dependent capillary damage during ischemia. J. Neurosci. 37, 129-140 (2017). 
196. Morcuende, S., Muñoz-Hernández, R., Benítez-Temiño, B., Pastor, A. M. \& de la Cruz, R. R. Neuroprotective effects of NGF, BDNF, NT-3 and GDNF on axotomized extraocular motoneurons in neonatal rats. Neuroscience 250, 31-48 (2013).

197. Ishitsuka, K. et al. Neurotrophin production in brain pericytes during hypoxia: a role of pericytes for neuroprotection. Microvasc. Res. 83, 352-359 (2012).

198. Shimizu, F. et al. Pericyte-derived glial cell line-derived neurotrophic factor increase the expression of claudin- 5 in the blood-brain barrier and the bloodnerve barrier. Neurochem. Res. 37, 401-409 (2012).

199. Bergers, G. \& Song, S. The role of pericytes in blood-vessel formation and maintenance. Neuro-Oncology 7, 452-464 (2005).

200. Eilken, H. M. et al. Pericytes regulate VEGF-induced endothelial sprouting through VEGFR1. Nat. Commun. 8, 1574 (2017).

201. Teichert, M. et al. Pericyte-expressed Tie2 controls angiogenesis and vessel maturation. Nat. Commun. 8, 16106 (2017).

202. Shen, J. et al. PDGFR- $\beta$ restores blood-brain barrier functions in a mouse model of focal cerebral ischemia. J. Cereb. Blood Flow. Metab. 39, 1501-1515 (2018).

203. Rustenhoven, J. et al. TGF-beta1 regulates human brain pericyte inflammatory processes involved in neurovasculature function. J. Neuroinflammation 13, 37 (2016).

204. Karow, M. et al. Direct pericyte-to-neuron reprogramming via unfolding of a neural stem cell-like program. Nat. Neurosci. 21, 932 (2018).

205. Karow, M. et al. Reprogramming of pericyte-derived cells of the adult human brain into induced neuronal cells. Cell Stem Cell 11, 471-476 (2012).

206. Duffield, J. S. Starting the scar: a primary role for pericytes? Nat. Med. 17, 1052-1053 (2011).

207. Reeves, C., Pradim-Jardim, A., Sisodiya, S. M., Thom, M. \& Liu, J. Y. W. Spatiotemporal dynamics of PDGFR $\beta$ expression in pericytes and glial scar formation in penetrating brain injuries in adults. Neuropathol. Appl. Neurobiol. 12539 (2019).

208. Sena, I. F. G. et al. Glioblastoma-activated pericytes support tumor growth via immunosuppression. Cancer Med. 7, 1232-1239 (2018).

209. Svensson, A., Özen, I., Genové, G., Paul, G. \& Bengzon, J. Endogenous brain pericytes are widely activated and contribute to mouse glioma microvasculature. PLoS ONE 10, e0123553 (2015).

210. Cheng, L. et al. Glioblastoma stem cells generate vascular pericytes to support vessel function and tumor growth. Cell 153, 139-152 (2013).

211. Nakagomi, T. et al. Brain vascular pericytes following ischemia have multipotential stem cell activity to differentiate into neural and vascular lineage cells. Stem Cells 33, 1962-1974 (2015).

212. Jeon, H.-M. et al. Crosstalk between glioma-initiating cells and endothelial cells drives tumor progression. Cancer Res. 74, 4482-4492 (2014).

213. Ribeiro, A. L. \& Okamoto, O. K. Combined effects of pericytes in the tumor microenvironment. Stem Cells Int. 868475 (2015).

214. Bourkoula, E. et al. Glioma-associated stem cells: a novel class of tumorsupporting cells able to predict prognosis of human low-grade gliomas. Stem Cells 32, 1239-1253 (2014).

215. Jackson, M., Hassiotou, F. \& Nowak, A. Glioblastoma stem-like cells: at the root of tumor recurrence and a therapeutic target. Carcinogenesis 36, 177-185 (2015).

216. Lathia, J. D., Mack, S. C., Mulkearns-Hubert, E. E., Valentim, C. L. L. \& Rich, J. N. Cancer stem cells in glioblastoma. Genes Dev. 29, 1203-1217 (2015).

217. Binello, E. \& Germano, I. M. Targeting glioma stem cells: a novel framework for brain tumors. Cancer Sci. 102, 1958-1966 (2011).

218. Sattiraju, A., Sai, K. K. S. \& Mintz, A. Glioblastoma stem cells and their microenvironment. Adv. Exp. Med. Biol. 1041, 119-140 (2017).

219. Park, T. I.-H. et al. Cultured pericytes from human brain show phenotypic and functional differences associated with differential CD90 expression. Sci. Rep. 6, 26587 (2016).

220. $\mathrm{Yi}, \mathrm{D}$. et al. Human glioblastoma-derived mesenchymal stem cell to pericytes transition and angiogenic capacity in glioblastoma microenvironment. Cell Physiol. Biochem. 46, 279-290 (2018).

221. Caspani, E. M., Crossley, P. H., Redondo-Garcia, C. \& Martinez, S. Glioblastoma: a pathogenic crosstalk between tumor cells and pericytes. PLOS ONE 9, e101402 (2014).

222. Eyler, C. E. et al. Glioma stem cell proliferation and tumor growth are promoted by nitric oxide synthase-2. Cell 146, 53-66 (2011).

223. Daneman, R. \& Prat, A. The blood-brain barrier. Cold Spring Harb. Perspect. Biol. 7 (2015).

224. Blanchette, M. \& Daneman, R. Formation and maintenance of the BBB. Mech. Dev. 138, 8-16 (2015).

225. Jiang, X. et al. Blood-brain barrier dysfunction and recovery after ischemic stroke. Prog. Neurobiol. 163-164, 144-171 (2018).

226. Sarkaria, J. N. et al. Is the blood-brain barrier really disrupted in all glioblastomas? A critical assessment of existing clinical data. Neuro-Oncology 20, 184-191 (2018).
227. van Tellingen, O. et al. Overcoming the blood-brain tumor barrier for effective glioblastoma treatment. Drug Resist. Updat. 19, 1-12 (2015).

228. Watkins, S. et al. Disruption of astrocyte-vascular coupling and the blood-brain barrier by invading glioma cells. Nat. Commun. 5, 4196 (2014).

229. Zhou, W. et al. Targeting glioma stem cell-derived pericytes disrupts the bloodtumor barrier and improves chemotherapeutic efficacy. Cell Stem Cell 21, 591-603.e4 (2017).

230. Seifert, S. \& Sontheimer, H. Bradykinin enhances invasion of malignant glioma into the brain parenchyma by inducing cells to undergo amoeboid migration. $J$. Physiol. 592, 5109-5127 (2014).

231. Liu, J., Jin, X., Liu, K. J. \& Liu, W. Matrix metalloproteinase-2-mediated occludin degradation and caveolin-1-mediated claudin-5 redistribution contribute to blood brain barrier damage in early ischemic stroke stage. J. Neurosci. 32 3044-3057 (2012)

232. Declèves, X., Amiel, A., Delattre, J.-Y. \& Scherrmann, J.-M. Role of ABC transporters in the chemoresistance of human gliomas. Curr. Cancer Drug Targets 6, 433-445 (2006).

233. Kemper, E. M. et al. Chemo-resistance of brain tumors: the role of the bloodbrain barrier with emphasis on P-glycoprotein. Cancer Res. 65, 970-970 (2005).

234. Da Ros, M. et al. Glioblastoma chemoresistance: the double play by microenvironment and blood-brain barrier. Int. J. Mol. Sci. 19, E2879 (2018).

235. Yan, G. et al. Evolution of blood-brain barrier damage associated with changes in brain metabolites following acute ischemia. Neuroreport 26, 945-951 (2015).

236. Charles, N. \& Holland, E. C. The perivascular niche microenvironment in brain tumor progression. Cell Cycle 9, 3012-3021 (2010).

237. Johansson, E. et al. CD44 interacts with HIF-2a to modulate the hypoxic phenotype of perinecrotic and perivascular glioma cells. Cell Rep. 20, 1641-1653 (2017).

238. Herold-Mende, C. \& Mock, A. Microenvironment and brain tumor stem cell maintenance: impact of the niche. Anticancer Agents Med. Chem. 14, 1065-1074 (2014).

239. Fidoamore, A. et al. Glioblastoma stem cells microenvironment: the paracrine roles of the niche in drug and radioresistance. Stem Cells Int. 6809105 (2016).

240. Cote, D. J., Dawood, H. Y. \& Smith, T. R. Venous thromboembolism in patients with high-grade glioma. Semin. Thromb. Hemost. 42, 877-883 (2016).

241. Perry, J. R. Thromboembolic disease in patients with high-grade glioma. NeuroOncology 14, iv73 (2012).

242. Cai, Y., Wu, J., Li, Z. \& Long, Q. Mathematical modelling of a brain tumour initiation and early development: a coupled model of glioblastoma growth, preexisting vessel co-option, angiogenesis and blood perfusion. PLOS ONE 11, e0150296 (2016).

243. Hoke, M. et al. Prognostic value of plasma d-dimer levels in patients with glioblastoma multiforme-results from a pilot study. Wien. Klin. Wochenschr. 123, 199-203 (2011).

244. Li, W. et al. Prognostic role of pretreatment plasma D-dimer in patients with solid tumors: a systematic review and meta-analysis. Cell. Physiol. Biochem. 45, 1663-1676 (2018)

245. Ivan, M. E. et al. Epidermal growth factor-like module containing mucin-like hormone receptor 2 expression in gliomas. J. Neurooncol. 121, 53-61 (2015).

246. Riedl, J. et al. Podoplanin expression in primary brain tumors induces platelet aggregation and increases risk of venous thromboembolism. Blood 129, 1831-1839 (2017)

247. Zwicker, J. I. Risking thromboembolism: podoplanin and glioma. Blood 129, 1742-1743 (2017)

248. Mitrugno, A., Tormoen, G. W., Kuhn, P. \& McCarty, O. J. T. The prothrombotic activity of cancer cells in the circulation. Blood Rev. 30, 11-19 (2016).

249. Demers, M. \& Wagner, D. D. NETosis: a new factor in tumor progression and cancer-associated thrombosis. Semin. Thromb. Hemost. 40, 277-283 (2014).

250. Grisold, W., Oberndorfer, S. \& Struhal, W. Stroke and cancer: a review. Acta Neurol. Scand. 119, 1-16 (2009).

251. Dardiotis, E. et al. Cancer-associated stroke: pathophysiology, detection and management. Int. J. Oncol. 54, 779-796 (2019).

252. Bang, O. Y. et al. Cancer cell-derived extracellular vesicles are associated with coagulopathy causing ischemic stroke via tissue factor-independent way: the OASIS-CANCER study. PLoS ONE 11, e0159170 (2016).

253. Iguchi, Y., Kimura, K., Kobayashi, K., Ueno, Y. \& Inoue, T. Ischaemic stroke with malignancy may often be caused by paradoxical embolism. J. Neurol. Neurosurg. Psychiatry 77, 1336-1339 (2006).

254. Dearborn, J. L., Urrutia, V. C. \& Zeiler, S. R. Stroke and cancer-a complicated relationship. J. Neurol. Transl. Neurosci. 2, 1039 (2014).

255. Yamanaka, K. et al. Subacute methotrexate encephalopathy mimicking ischemic stroke with dynamic changes on magnetic resonance imaging. J. Stroke Cerebrovasc. Dis. 27, e233-e235 (2018).

256. El Amrani, M. et al. Brain infarction following 5-fluorouracil and cisplatin therapy Neurology 51, 899 (1998). 
257. Li, S.H. et al. Incidence of ischemic stroke post-chemotherapy: a retrospective review of 10,963 patients. Clin. Neurol. Neurosurg. 108, 150-156 (2006).

258. Fraum, T. J., Kreisl, T. N., Sul, J., Fine, H. A. \& Iwamoto, F. M. Ischemic stroke and intracranial hemorrhage in glioma patients on antiangiogenic therapy. J. Neurooncol. 105, 281-289 (2011).

259. Suero-Abreu, G. A., Cheng, J. Z. \& Then, R. K. Multiple recurrent ischaemic strokes in a patient with cancer: is there a role for the initiation of anticoagulation therapy for secondary stroke prevention? Case Rep., bcr-2016-218105 (2017).

260. Auer, T. A., Renovanz, M., Marini, F., Brockmann, M. A. \& Tanyildizi, Y. Ischemic stroke and intracranial hemorrhage in patients with recurrent glioblastoma multiforme, treated with bevacizumab. J. Neurooncol. 133, 571-579 (2017).

261. Seet, R. C. S., Rabinstein, A. A., Lindell, P. E., Uhm, J. H. \& Wijdicks, E. F. Cerebrovascular events after bevacizumab treatment: an early and severe complication. Neurocrit. Care 15, 421-427 (2011).

262. Zuo, P.-Y., Chen, X.-L., Liu, Y.-W., Xiao, C.-L. \& Liu, C.-Y. Increased risk of cerebrovascular events in patients with cancer treated with bevacizumab: a metaanalysis. PLOS ONE 9, e102484 (2014).

263. Shichita, T., Sakaguchi, R., Suzuki, M. \& Yoshimura, A. Post-ischemic inflammation in the brain. Front. Immunol. 3, 132 (2012).

264. Kawabori, M. \& Yenari, M. A. Inflammatory responses in brain ischemia. Curr. Med. Chem. 22, 1258-1277 (2015).

265. Harari, O. A. \& Liao, J. K. NF-KB and innate immunity in ischemic stroke. Ann. N.Y. Acad. Sci. 1207, 32-40 (2010)

266. Hui, Xie, Patricio, Ray, \&, E. \& Lou, ShortBillie NF-KB activation plays a role in superoxide-mediated cerebral endothelial dysfunction after hypoxia/reoxygenation. Stroke 36, 1047-1052 (2005)

267. Tew, K. D. \& Townsend, D. M. Redox platforms in cancer drug discovery and development. Curr. Opin. Chem. Biol. 15, 156-161 (2011).

268. Siegelin, M. D., Reuss, D. E., Habel, A., Rami, A. \& von Deimling, A. Quercetin promotes degradation of survivin and thereby enhances deathreceptor-mediated apoptosis in glioma cells. Neuro-Oncol. 11, 122-131 (2009).

269. Kim, H., Moon, J. Y., Ahn, K. S. \& Cho, S. K. Quercetin induces mitochondrial mediated apoptosis and protective autophagy in human glioblastoma U373MG cells. Oxid. Med. Cell. Longev. 596496 (2013).

270. Vauzour, D., Vafeiadou, K., Rodriguez-Mateos, A., Rendeiro, C. \& Spencer, J. P. E. The neuroprotective potential of flavonoids: a multiplicity of effects. Genes Nutr. 3, 115-126 (2008).

271. Li, F.-Q., Wang, T., Pei, Z., Liu, B. \& Hong, J.-S. Inhibition of microglial activation by the herbal flavonoid baicalein attenuates inflammation-mediated degeneration of dopaminergic neurons. J. Neural Transm. 112, 331-347 (2005).

272. Masheta, D. Q. \& Al-Azzawi, S. K. Antioxidant and anti-inflammatory effects of delphinidin on glial cells and lack of effect on secretase enzyme. IOP Conf. Ser. Mater. Sci. Eng. 454, 012061 (2018).

273. Rezai-Zadeh, K. et al. Apigenin and luteolin modulate microglial activation via inhibition of STAT1-induced CD40 expression. J. Neuroinflammation 5, 41 (2008).

274. Matias, I., Buosi, A. S. \& Gomes, F. C. A. Functions of flavonoids in the central nervous system: Astrocytes as targets for natural compounds. Neurochem. Int. 95, 85-91 (2016).

275. Santos, B. L. et al. Flavonoids suppress human glioblastoma cell growth by inhibiting cell metabolism, migration, and by regulating extracellular matrix proteins and metalloproteinases expression. Chem. Biol. Interact. 242, 123-138 (2015).

276. Freitas, S. et al. Flavonoids inhibit angiogenic cytokine production by human glioma cells. Phytother. Res. 25, 916-921 (2011).

277. Vidak, M., Rozman, D. \& Komel, R. Effects of flavonoids from food and dietary supplements on glial and glioblastoma multiforme cells. Molecules 20, 19406-19432 (2015).

278. Lee, S.-H. et al. Antitumor activity of methyl gallate by inhibition of focal adhesion formation and Akt phosphorylation in glioma cells. Biochim. Biophys. Acta 1830, 4017-4029 (2013).

279. Sun, J. et al. Neuroprotective effects of gallic acid against hypoxia/reoxygenation-induced mitochondrial dysfunctions in vitro and cerebral ischemia/reperfusion injury in vivo. Brain Res. 1589, 126-139 (2014).

280. Farbood, Y., Sarkaki, A., Hashemi, S., Mansouri, M. T. \& Dianat, M. The effects of gallic acid on pain and memory following transient global ischemia/reperfusion in Wistar rats. Avicenna. J. Phytomed. 3, 329-340 (2013).

281. Xu, C., Wu, X. \& Zhu, J. VEGF promotes proliferation of human glioblastoma multiforme stem-like cells through VEGF receptor 2. ScientificWorldJournal, 417413 (2013)

282. Zhang, Y. et al. Melatonin antagonizes hypoxia-mediated glioblastoma cell migration and invasion via inhibition of HIF-1a. J. Pineal Res. 55, 121-130 (2013).

283. Jiang, F.-S. et al. Cardamonin regulates miR-21 expression and suppresses angiogenesis induced by vascular endothelial growth factor. BioMed. Res. Int. 114, 2197-2206 (2015)
284. Kim, Y.-J. et al. Dimethyl cardamonin inhibits lipopolysaccharide-induced inflammatory factors through blocking NF-kappaB p65 activation. Int. Immunopharmacol. 10, 1127-1134 (2010).

285. Bubici, C., Papa, S., Pham, C. G., Zazzeroni, F. \& Franzoso, G. The NF-kappaBmediated control of ROS and JNK signaling. Histol. Histopathol. 21, 69-80 (2006).

286. Xu, L., Botchway, B. O. A., Zhang, S., Zhou, J. \& Liu, X. Inhibition of NF-KB signaling pathway by resveratrol improves spinal cord injury. Front. Neurosci. 12, 690 (2018).

287. Zagrean, A.-M., Hermann, D. M., Opris, I., Zagrean, L. \& Popa-Wagner, A. Multicellular crosstalk between exosomes and the neurovascular unit after cerebral ischemia. Therapeutic implications. Front. Neurosci. 12, 811 (2018).

288. Murgoci, A.-N. et al. Brain-cortex microglia-derived exosomes: nanoparticles for glioma therapy. Chemphyschem . 19, 1205-1214 (2018).

289. Liu, Y., Fu, N., Su, J., Wang, X. \& Li, X. Rapid enkephalin delivery using exosomes to promote neurons recovery in ischemic stroke by inhibiting neuronal p53/ Caspase-3. BioMed. Res. Int. 4273290 (2019).

290. Bhowmik, A. et al. Anti-SSTR2 peptide based targeted delivery of potent PLGA encapsulated 3,3'-diindolylmethane nanoparticles through blood brain barrier prevents glioma progression. Oncotarget 8, 65339-65358 (2017).

291. Ji, Y. et al. DhHP-6 attenuates cerebral ischemia-reperfusion injury in rats through the inhibition of apoptosis. Mol. Med. Rep. 16, 7229-7236 (2017).

292. Tu, J. et al. Cell-permeable peptide targeting the Nrf2-Keap1 interaction: a potential novel therapy for global cerebral ischemia. J. Neurosci. 35, 14727-14739 (2015).

293. Zhang, C.-X. et al. Mitochondria-targeted cyclosporin A delivery system to treat myocardial ischemia reperfusion injury of rats. J. Nanobiotechnol. 17, 18 (2019).

294. Yang, J., Zhang, X., Chen, X., Wang, L. \& Yang, G. Exosome mediated delivery of miR-124 promotes neurogenesis after ischemia. Mol. Ther. Nucleic Acids 7 , 278-287 (2017).

295. Zhang, H. et al. Exosome-mediated targeted delivery of miR-210 for angiogenic therapy after cerebral ischemia in mice. J. Nanobiotechnol. 17, 29 (2019).

296. Geng, W. et al. Exosomes from miRNA-126-modified ADSCs promotes functional recovery after stroke in rats by improving neurogenesis and suppressing microglia activation. Am. J. Transl. Res. 11, 780-792 (2019).

297. Choudhury, R. Hypoxia and hyperbaric oxygen therapy: a review. Int. J. Gen. Med. 11, 431-442 (2018).

298. Liska, G. M., Lippert, T., Russo, E., Nieves, N. \& Borlongan, C. V. A dual role for hyperbaric oxygen in stroke neuroprotection: preconditioning of the brain and stem cells. Cond. Med. 1, 151-166 (2018).

299. Matchett, G. A., Martin, R. D. \& Zhang, J. H. Hyperbaric oxygen therapy and cerebral ischemia: neuroprotective mechanisms. Neurol. Res. 31, 114-121 (2009).

300. Chen, J., Xu, H., Ding, J. \& Qin, Z. Radiotherapy after hyperbaric oxygenation in malignant gliomas. Curr. Med. Res. Opin. 31, 1977-1984 (2015).

301. Duan, S., Shao, G., Yu, L. \& Ren, C. Angiogenesis contributes to the neuroprotection induced by hyperbaric oxygen preconditioning against focal cerebral ischemia in rats. Int. J. Neurosci. 125, 625-634 (2015).

302. Michalski, D., Härtig, W., Schneider, D. \& Hobohm, C. Use of normobaric and hyperbaric oxygen in acute focal cerebral ischemia-a preclinical and clinical review. Acta Neurol. Scand. 123, 85-97 (2011).

303. Francis, A. \& Baynosa, R. Ischaemia-reperfusion injury and hyperbaric oxygen pathways: a review of cellular mechanisms. Diving Hyperb. Med. 47, 110-117 (2017).

304. WANG, Y.-G. et al. Hyperbaric oxygen promotes malignant glioma cell growth and inhibits cell apoptosis. Oncol. Lett. 10, 189-195 (2015).

305. Stępień, K., Ostrowski, R. P. \& Matyja, E. Hyperbaric oxygen as an adjunctive therapy in treatment of malignancies, including brain tumours. Med. Oncol. 33, 101 (2016).

306. Huang, L., Boling, W. \& Zhang, J. H. Hyperbaric oxygen therapy as adjunctive strategy in treatment of glioblastoma multiforme. Med. Gas Res. 8, 24-28 (2018).

307. Han, M. H. et al. Induction of apoptosis by sanguinarine in C6 rat glioblastoma cells is associated with the modulation of the Bcl-2 family and activation of caspases through downregulation of extracellular signal-regulated kinase and Akt. Anticancer Drugs 18, 913-921 (2007).

308. Pallichankandy, S., Rahman, A., Thayyullathil, F. \& Galadari, S. ROS-dependent activation of autophagy is a critical mechanism for the induction of anti-glioma effect of sanguinarine. Free Radic. Biol. Med. 89, 708-720 (2015).

309. Wang, Q. et al. Anti-inflammatory and neuroprotective effects of sanguinarine following cerebral ischemia in rats. Exp. Ther. Med. 13, 263-268 (2017).

310. Gong, G. et al. Protective effect of glycyrrhizin, a direct HMGB1 inhibitor, on focal cerebral ischemia/reperfusion-induced inflammation, oxidative stress, and apoptosis in rats. PLOS ONE 9, e89450 (2014).

311. Chen, T. C., Fonseca, C. O. D. \& Schönthal, A. H. Preclinical development and clinical use of perillyl alcohol for chemoprevention and cancer therapy. Am. J. Cancer Res. 5, 1580-1593 (2015). 
The interrelationship between cerebral ischemic stroke and glioma: a... Ghosh et al.

312. Xu, L., Li, Y., Fu, Q. \& Ma, S. Perillaldehyde attenuates cerebral ischemiareperfusion injury-triggered overexpression of inflammatory cytokines via modulating Akt/JNK pathway in the rat brain cortex. Biochem. Biophys. Res. Commun. 454, 65-70 (2014).

313. Bhattacharya, P., Pandey, A. K., Paul, S. \& Patnaik, R. Neuroprotective potential of Piroxicam in cerebral ischemia: an in silico evaluation of the hypothesis to explore its therapeutic efficacy by inhibition of aquaporin-4 and acid sensing ion channel1a. Med. Hypotheses 79, 352-357 (2012).

314. Liu, X. et al. Salidroside provides neuroprotection by modulating microglial polarization after cerebral ischemia. J. Neuroinflammation 15, 39 (2018).

315. Zhang, Y. et al. Effects of salidroside on glioma formation and growth inhibition together with improvement of tumor microenvironment. Chin. J. Cancer Res. Chung-Kuo Yen Cheng Yen Chiu 25, 520-526 (2013).

316. Ni, J., Li, Y., Li, W. \& Guo, R. Salidroside protects against foam cell formation and apoptosis, possibly via the MAPK and AKT signaling pathways. Lipids Health Dis. 16, 198 (2017).

317. Li, B., Wang, F., Liu, N., Shen, W. \& Huang, T. Astragaloside IV inhibits progression of glioma via blocking MAPK/ERK signaling pathway. Biochem. Biophys. Res. Commun. 491, 98-103 (2017).

318. Li, M. et al. Astragaloside IV protects against focal cerebral ischemia/reperfusion injury correlating to suppression of neutrophils adhesion-related molecules. Neurochem. Int. 60, 458-465 (2012).

319. Turkez, H., Tozlu, O. O., Lima, T. C., de Brito, A. E. M. \& de Sousa, D. P. A Comparative evaluation of the cytotoxic and antioxidant activity of Mentha crispa essential oil, its major constituent Rotundifolone, and analogues on human glioblastoma. Oxid. Med. Cell. Longev. 2083923 (2018).

320. Aas, A. T., Tønnessen, T. I., Brun, A. \& Salford, L. G. Growth inhibition of rat glioma cells in vitro and in vivo by aspirin. J. Neurooncol. 24, 171-180 (1995).

321. Yan, B. C. et al. Neuroprotective effect of a new synthetic aspirin-decursinol adduct in experimental animal models of ischemic stroke. PLOS ONE 8, e74886 (2013).

322. Algra, A. \& van Gijn, J. Cumulative meta-analysis of aspirin efficacy after cerebral ischaemia of arterial origin. J. Neurol. Neurosurg. Psychiatry 66, 255 (1999).
323. Xu, W. et al. Neuroprotective effects of stem cells in ischemic stroke. Stem Cells Int. 4653936 (2017)

324. Marei, H. E. et al. Potential of stem cell-based therapy for ischemic stroke. Front Neurol. 9 (2018)

325. Abe, K. et al. Stem cell therapy for cerebral ischemia: from basic science to clinical applications. J. Cereb. Blood Flow. Metab. 32, 1317-1331 (2012).

326. Vahidy Farhaan, S. et al. Systematic review and meta-analysis of bone marrowderived mononuclear cells in animal models of ischemic stroke. Stroke 47, 1632-1639 (2016).

327. Chan, H. H., Wathen, C. A., Ni, M. \& Zhuo, S. Stem cell therapies for ischemic stroke: current animal models, clinical trials and biomaterials. RSC Adv. 7, 18668-18680 (2017).

328. Shiota, Y. et al. Transplantation of a bone marrow mesenchymal stem cell line increases neuronal progenitor cell migration in a cerebral ischemia animal model. Sci. Rep. 8, 14951 (2018).

Open Access This article is licensed under a Creative Commons Attribution 4.0 International License, which permits use, sharing, adaptation, distribution and reproduction in any medium or format, as long as you give appropriate credit to the original author(s) and the source, provide a link to the Creative Commons license, and indicate if changes were made. The images or other third party material in this article are included in the article's Creative Commons license, unless indicated otherwise in a credit line to the material. If material is not included in the article's Creative Commons license and your intended use is not permitted by statutory regulation or exceeds the permitted use, you will need to obtain permission directly from the copyright holder. To view a copy of this license, visit http://creativecommons. org/licenses/by/4.0/.

(c) The Author(s) 2019 